\title{
The role of El Niño in the global energy redistribution: a case study in the mid-Holocene
}

\author{
Marion Saint-Lu, ${ }^{a, *}$, Pascale Braconnot ${ }^{a}$, Julie Leloup $^{b}$, Olivier Marti $^{a}$ \\ *Corresponding author: marion.saint-lu@lsce.ipsl.fr \\ a Laboratoire des Sciences du Climat et de I'Environnement, LSCE/IPSL, CEA-CNRS-UVSQ, Université Paris-Saclay, F-91191 Gif-sur- \\ Yvette, France \\ b Sorbonne Universités, UPMC Univ. Paris 06, Laboratoire d'Océanographie et Climatologie, LOCEAN/IPSL, UMR 7159, CNRS-IRD- \\ MNHN, 4, place Jussieu, 75005 Paris, France
}

\begin{abstract}
It has been shown that El Niño events contribute to discharge the warm pool excess of energy out of the tropical Pacific. In a different climate, the energetic budget in the tropical Pacific is altered, which might have an effect on the El Niño amplitude and/or occurrence and thereby on the role of El Niño on energy redistribution. The mid-Holocene period (6 ka BP) offers a good example of changes in the distribution of incoming solar energy. In particular, the equator-pole gradient was weaker compared to the modern period. We analyze long stable simulations of the mid-Holocene and the pre-industrial era and discuss the mean- and $\mathrm{El}$ Niño-related energy transports in the two climates. We show that the role of global energy pump played by the tropical Pacific is reduced in the mid-Holocene in our simulation, both in long-term mean and during El Niño years. We demonstrate that this is not only a direct response to insolation forcing but this is further amplified by changes in internal processes. We analyze the relative role of El Niño events in the Pacific discharge in the two climates and show that it is reduced in the mid-Holocene, i.e. the fraction of the Pacific discharge that is due to El Niño is reduced. This is mainly due to reduction in the occurrence of El Niño events. This work gives a new approach to address El Niño changes, from the perspective of the role of El Niño in global energy redistribution.
\end{abstract}

\section{Introduction}

The tropical band is a source of energy for the whole planet, as it receives the most solar radiations annually. If general oceanic and atmospheric circulations redistribute the energy on Earth, from the sources to the sinks (Fasullo and Trenberth, 2008), interannual variability also plays a role in redistributing the energy. In the tropical Pacific, the dominant source of interannual variability in the energetic budget is the El Niño/Southern Oscillation (ENSO) (Mayer and Haimberger, 2012). El Niño events are associated with a heat discharge of the western Pacific warm pool (Trenberth et al, 2002). This region is a powerful source of energy for the planet, since it accumulates oceanic heat (Bjerknes, 1969; Wyrtki, 1975). As a consequence, El Niño events are associated with a warming of global mean surface air temperature (Trenberth and Fasullo, 2013).

During El Niño events, oceanic heat propagates from the western Pacific warm pool to the eastern Pacific (Wyrtki, 1975; Hasegawa and Hanawa, 2003). Sea surface temperature (SST) cools in the warm pool and warms in the central-eastern (CE) Pacific. This warming is associated with evaporative cooling, turning the oceanic heat into atmospheric latent heat, which is then released when condensation occurs (Trenberth et al, 2002). This warms the atmospheric column over the CE Pacific and weakens the Walker circulation (Trenberth et al, 2002; Mayer et al, 2013). This results in an anomalous divergence of the atmospheric horizontal transport of energy (moist static energy) above the CE Pacific (Trenberth et al, 2002). Mayer et al (2013) showed that the energy coming from this oceanic discharge is redistributed globally mainly via El Niño-related changes in the atmospheric circulation (Klein et al, 1999). More specifically, the Pacific Hadley cell is strengthened and the Walker cell is weakened (Oort and Yienger, 1996). Mayer et al (2014) further showed that the energy is mainly brought to the tropical Atlantic and Indian oceans. The poleward export is negligible because the El Niño-related changes in the Hadley circulations in the three basins compensate each other. Thus, the El Niño-related energy export out of the tropical Pacific is performed mainly by the atmosphere. Oceanic transports of energy are negligible, except through the Indonesian Throughflow (Mayer et al, 2014; McGregor et al, 2014). Note that the Sverdrup transport associated with the recharge oscillator theory (Jin, 1997) takes action in the offequatorial band, at around $5^{\circ} \mathrm{N}$ and $5^{\circ} \mathrm{S}$ and does not contribute to export the energy out of the tropical Pacific (Mayer et al, 2014). 
Here we investigate the role of El Niño in the Earth's energy redistribution, comparing simulations of the mid-Holocene (MH, 6 ka BP) and the pre-industrial era (PI, 0 ka BP) performed with the Earth System Model IPSL-CM5A-LR (Marti et al, 2010; Dufresne et al, 2013).

The MH period is characterized by a reduction in the tropics-poles gradient of incoming insolation, due to increased Earth's obliquity, along with an amplification of the annual cycle of insolation in the northern hemisphere, due to equinoxes precession (see Fig. 1). This induces changes in the meridional heat transport (Braconnot et al, 2000). In particular, the boreal summer monsoon, which is stronger in the MH (Kutzbach and Otto-Bliesner, 1982; Joussaume et al, 1999), plays a dominant role in transporting the energy (Braconnot et al, 2008).

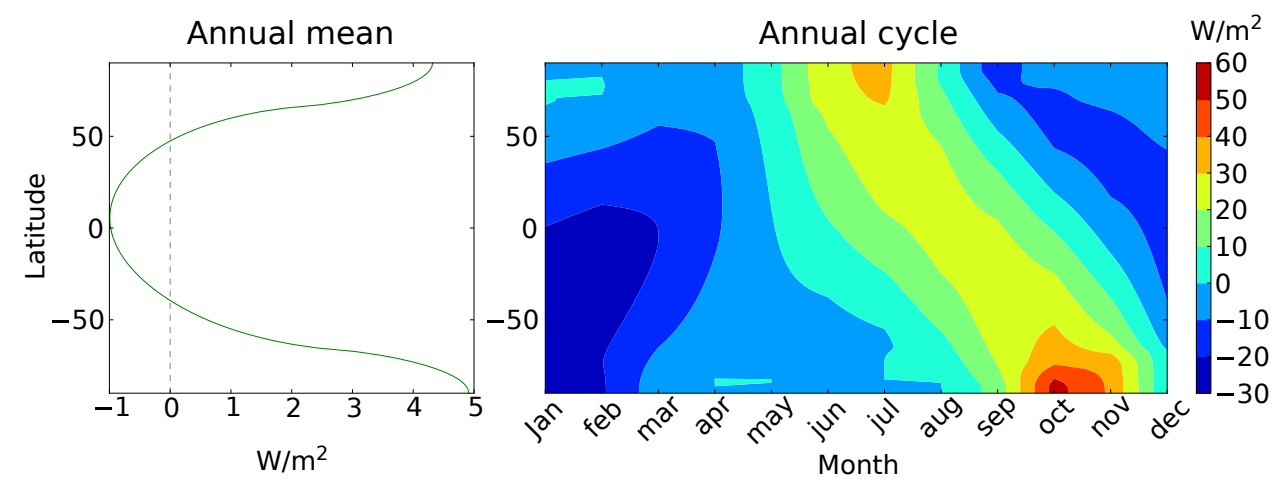

Fig. 1. Mid-Holocene insolation forcing. Left: MH-PI difference in the annual mean insolation (TOA incoming shortwave radiations) as a function of latitude $\left(\mathrm{W} / \mathrm{m}^{2}\right)$. Right: $\mathrm{MH}-\mathrm{PI}$ difference in the mean annual cycle of insolation as a function of latitude $\left(\mathrm{W} / \mathrm{m}^{2}\right)$.

ENSO variability was shown to be reduced in the MH, from numerous model studies (Clement et al, 2000; Liu et al, 2000; Zheng et al, 2008; An and Choi, 2013) and paleodata (Tudhope et al, 2001; Moy et al, 2002; McGregor and Gagan, 2004; Duprey et al, 2012; Sadekov et al, 2013; Cobb et al, 2013; Carré et al, 2013), although exact quantification differ from model results (Brown et al, 2008; Emile-Geay et al, 2015). It has been hypothesized that this ENSO reduction is due to the stronger monsoon, through changes in the easterly winds strength and seasonal cycle over the Pacific (Liu et al, 2000; Liu, 2002; Pan et al, 2005; Braconnot et al, 2012b; Luan et al, 2012).

Addressing El Niño changes associated with the MH period (compared to the modern climate) with an energetic approach has not been done so far. This approach may help to understand the MH El Niño changes and the energetic role of El Niño in a different climate. In this study we focus on the El Niño phase of ENSO.

This paper is organized as follows: section 2 gives the characteristics of the $\mathrm{MH}$ period, concerning long-term mean and El Niño-years, first describing the model and experiments; section 3 details the energetic budget in the PI period, in long-term mean and El Niño-years, giving the energetic equations and calculation framework; section 4 describes energetic changes associated with the MH period, in longterm mean and El Niño-years; section 5 discusses the El Niño relative role in the Pacific discharge and compares it between the two periods; finally, summary and discussion are found in section 6 .

\section{Simulated changes between mid-Holocene and pre-industrial}

\subsection{Model and experiments}

Simulations of the mid-Holocene period (MH, $6 \mathrm{ka} \mathrm{BP})$ and the pre-industrial era (PI, $0 \mathrm{ka}$ BP) were performed with the Earth System Model IPSL-CM5A-LR (Marti et al, 2010; Dufresne et al, 2013). This model couples the atmosphere model LMDZ (Hourdin et al, 2006) to the ocean model NEMO/OPA (Madec et al, 1997), using the coupler OASIS (Valcke, 2006). The atmosphere model has an horizontal resolution of $96 \times 96$ grid points, and a vertical resolution of 39 levels. The ocean model has a resolution of 182 grid points in longitude $\times 149$ in latitude $\times 31$ vertical levels. The land surface model ORCHIDEE (Krinner et al, 2005) is coupled to the atmosphere model, and the sea-ice model LIM2 (Fichefet and Maqueda, 1997) is coupled to both atmosphere and ocean models. The model includes an interactive carbon cycle, and a river runoff scheme closes the water budget between land and ocean. The model does not use dynamic vegetation. Vegetation is prescribed to modern condition. However the model has interactive carbon cycle and leaf area index, inducing a vegetation feedback in the $\mathrm{MH}$ simulation (Kageyama et al, 2013; Braconnot and Kageyama, 2015). 
The PI experiment is computed using 1860 conditions of greenhouse gases, aerosols, land use, ice-sheets and topography, following the last Coupled Model Intercomparison Project (CMIP5) protocol (Taylor et al, 2012). The simulation is stable and 1000-year long. It is used as the reference for the modern climate. The main features of the tropical Pacific are reproduced in the IPSL-CM5A-LR model, with some biases common to many coupled climate models (Dufresne et al, 2013). The equatorial upwelling extends too far west, associated with too strong equatorial easterlies. This contributes to erode the warm pool. The South Pacific Convergence Zone (SPCZ) is too zonally-oriented. The double Inter-Tropical Convergence Zone (ITCZ) is too pronounced in the south eastern Pacific, which induces a semi-annual SST cycle in the upwelling region. ENSO variability is properly reproduced, even though both dynamic and thermodynamic feedbacks are smaller than observed (Bellenger et al, 2014).

The MH experiment (Kageyama et al, 2013) follows the Paleoclimate Modeling Inter-comparison Project phase 3 (PMIP3) framework (Braconnot et al, 2012a). We consider the last 500 years of this simulation, which are stable and at equilibrium. The top-of-atmosphere (TOA) incoming solar radiation is computed using the Earth's orbital parameters (eccentricity, obliquity, precession) of 6 ka BP (Berger, 1978). Compared to the present day, equinoxes and solstices are rotated by about $90^{\circ}$ along the Earth's orbit, and obliquity is increased by $0.7^{\circ}$. Therefore, the annual cycle is amplified in the northern hemisphere and weakened in the southern hemisphere. Higher obliquity reduces insolation in the tropics and increases it in the high latitudes. It prevails in the annual mean insolation forcing, and leads to a reduction of $1 \mathrm{~W} / \mathrm{m}^{2}$ at the equator and an increase of about $4.5 \mathrm{~W} / \mathrm{m}^{2}$ at the poles (Fig. 1). The main features simulated by this experiment are very similar to those simulated by the previous version of the IPSL model (IPSL-CM4-LR), discussed in Luan et al (2012); Braconnot et al (2012b); Luan et al (2015).

\subsection{Mean state changes}

Figure 2 shows the long-term mean changes in surface temperature and rainfall associated with the $\mathrm{MH}$, compared to the PI. Tropics are colder and dryer, about $-0.3^{\circ} \mathrm{C}$ and $-0.1 \mathrm{~mm} /$ day in the equatorial band, which is in the range of the PMIP3 multi-model ensemble (An and Choi, 2013). These are robust meanstate features of the MH (Zheng et al, 2008; An and Choi, 2013). This tropical cooling is mainly due to the obliquity increase, which also acts to weaken the mean meridional temperature gradient between low and high latitudes (Mantsis et al, 2011). Equinoxes precession also plays a substantial role in cooling the tropics, as pointed out by Luan et al (2012), by extending the boreal winter season (187 days from the winter solstice to the summer solstice at $6 \mathrm{ka}$, against 182 days at $0 \mathrm{ka})$.

Zonal averages
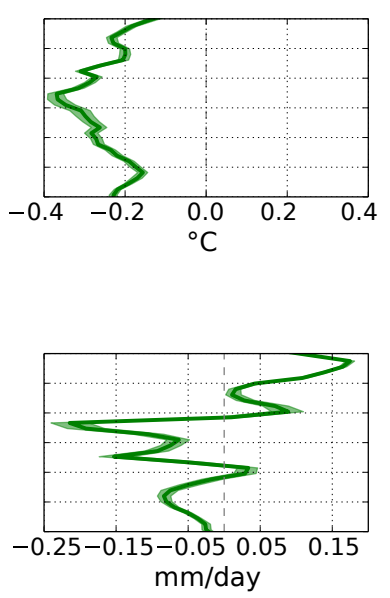

Surface temperature (SST over the ocean) \& surface winds

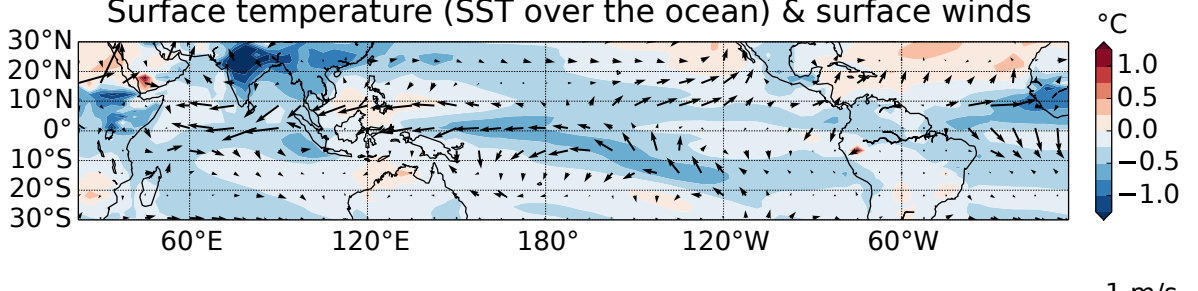

Rainfall \& surface winds

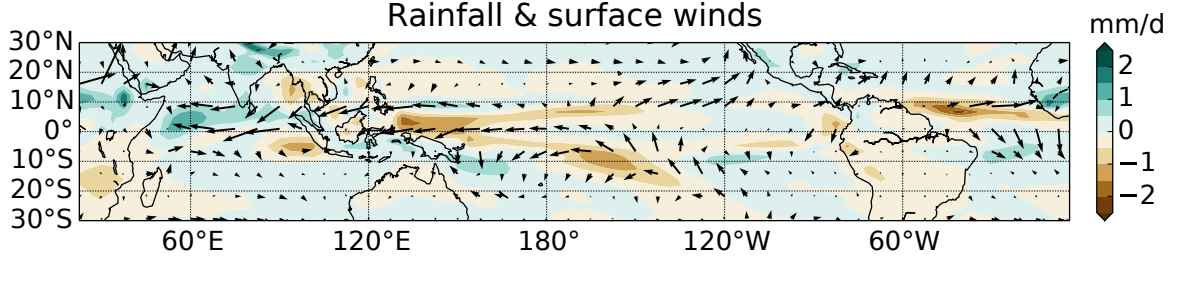

Fig. 2. MH-PI mean state differences. Right panel: MH-PI difference in the long-term mean surface temperature (SST over the ocean; top, ${ }^{\circ} \mathrm{C}$ ), rainfall (bottom, $\mathrm{mm} /$ day) and surface winds (top \& bottom, $\mathrm{m} / \mathrm{s}$ ) in the tropical band. Left panel: zonal average of the surface temperature change $\left(\right.$ top,${ }^{\circ} \mathrm{C}$ ) and of the rainfall change (bottom, mm/day). Incertitude ranges on left panel give the $90 \%$ confidence intervals, estimated from bootstrap resampling (see Methods).

Stronger mean rainfall over India and Africa (Fig. 2) is the signature of monsoon intensification in summer, which is also a robust feature of the MH (Joussaume et al, 1999; Zhao et al, 2005; Zhao and Harrison, 2011). Boreal summer is warmer in the northern hemisphere due to increased summer insolation (which is not visible in Fig. 2 because summer warming is balanced by winter cooling on annual mean; see Kageyama et al 2013 for global maps with IPSL-CM5A-LR model). Since continents warm more than oceans, the large-scale redistribution of energy between land and sea strengthens pressure gradients and 
intensifies the Asian and African monsoons (Kutzbach and Otto-Bliesner, 1982; Braconnot et al, 2008). As a consequence, long-term mean rainfall shows wetter conditions between $10^{\circ} \mathrm{N}$ and $35^{\circ} \mathrm{N}$ (of up to $+0.15 \mathrm{~mm} /$ day) when zonally averaged (Fig. 2).

By mass conservation, the Asian monsoon intensification strengthens the long-term mean easterly winds from the central Pacific to the Indian ocean (Fig. 2) (Liu et al, 2000; Zheng et al, 2008; Braconnot et al, 2012b). Easterly winds are even stronger over cooling areas, suggesting that their strengthening is amplified by wind-evaporation-SST (WES) feedback. Clement et al (2000) also suggested that the easterly wind strengthening is due to zonal asymmetry in the atmospheric response to boreal summer heating, which is stronger in the western Pacific where deep convection makes it more sensitive to SST changes. Luan et al (2012) came to similar conclusions, invoking different cloud radiative forcing between west and east.

Figure 3 is a vertical section of the ocean-atmosphere circulation along the equator in the Indo-Pacific region. Easterly winds strengthening deepens the thermocline in the western equatorial Pacific, as pointed out by Luan et al (2012). It follows that the equatorial Pacific thermocline is more tilted in the $\mathrm{MH}$ than in the PI. These long-term mean changes in the thermocline depth are not perceptible from the changes in SSTs, namely much colder SSTs in the west than in the east. SSTs are more strongly affected by evaporation and heat fluxes. Easterly winds strengthening is also associated with a slight westward shift of the ascending branch of the Walker circulation.

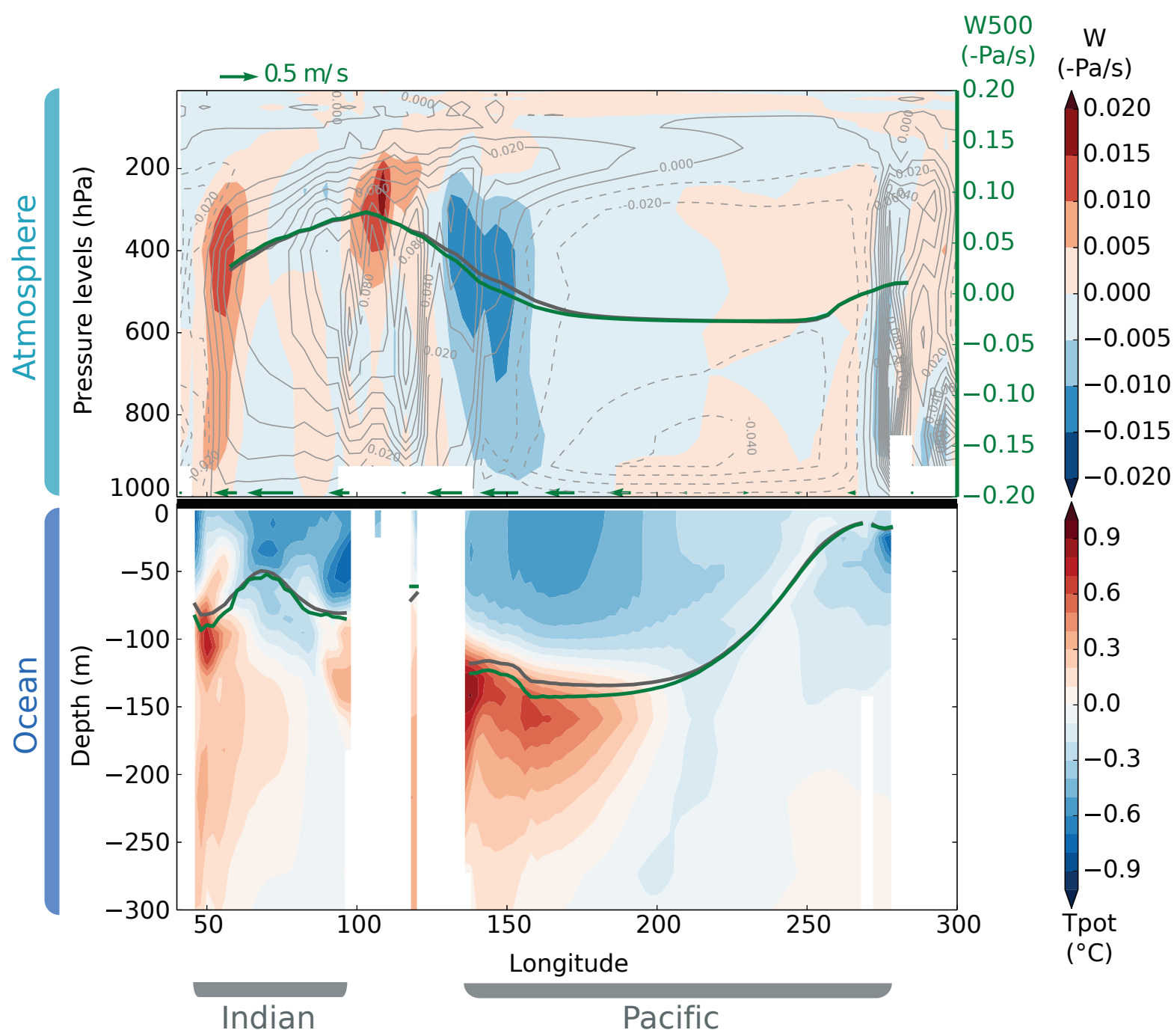

Fig. 3. MH mean state changes relative to $\mathrm{PI}$, in the equatorial band $\left(2^{\circ} \mathrm{N}-2^{\circ} \mathrm{S}\right)$, atmosphere-ocean vertical section. Top: atmospheric vertical section $\left(2^{\circ} \mathrm{N}-2^{\circ} \mathrm{S}\right)$; MH-PI vertical velocity $w$ (colors, -Pa/s, red meaning upward motion and blue meaning downward motion) and PI vertical velocity (contours, $-\mathrm{Pa} / \mathrm{s}$ ); vertical velocity at 500 mb $w 500$ in the $\mathrm{MH}$ (green curve) and in the PI (black curve) (right axis, -Pa/s); MH-PI difference in the zonal wind at $10 \mathrm{~m}$ (green arrows, $\mathrm{m} / \mathrm{s})$. Bottom: oceanic vertical section $\left(2^{\circ} \mathrm{N}-2^{\circ} \mathrm{S}\right) ; \mathrm{MH}-\mathrm{PI}$ difference in the potential temperature $T p o t\left(\operatorname{colors},{ }^{\circ} \mathrm{C}\right)$; thermocline depth in the MH (green curve) and in the PI (black curve). The thermocline depth is defined as the depth of maximum potential temperature gradient $(\mathrm{m})$. 


\section{$2.3 \quad$ El Niño changes}

We investigate the MH El Niño characteristics in the IPSL-CM5A-LR model. Standard deviation of SSTs, filtered on the ENSO-band (2-8 years), is overall reduced in the MH, especially over the equatorial Pacific (Fig. 4). When using the common index Niño3 or Niño3.4 (standard deviation of monthly SST in the corresponding region ${ }^{1}$ ), it is reduced in the $\mathrm{MH}$, and this reduction is about $20 \%$ greater in IPSLCM5A-LR than estimated from the PMIP3 ensemble mean (An and Choi, 2013) (Tab. 1). This reduction is in agreement with paleodata although slightly underestimated (Emile-Geay et al, 2015).

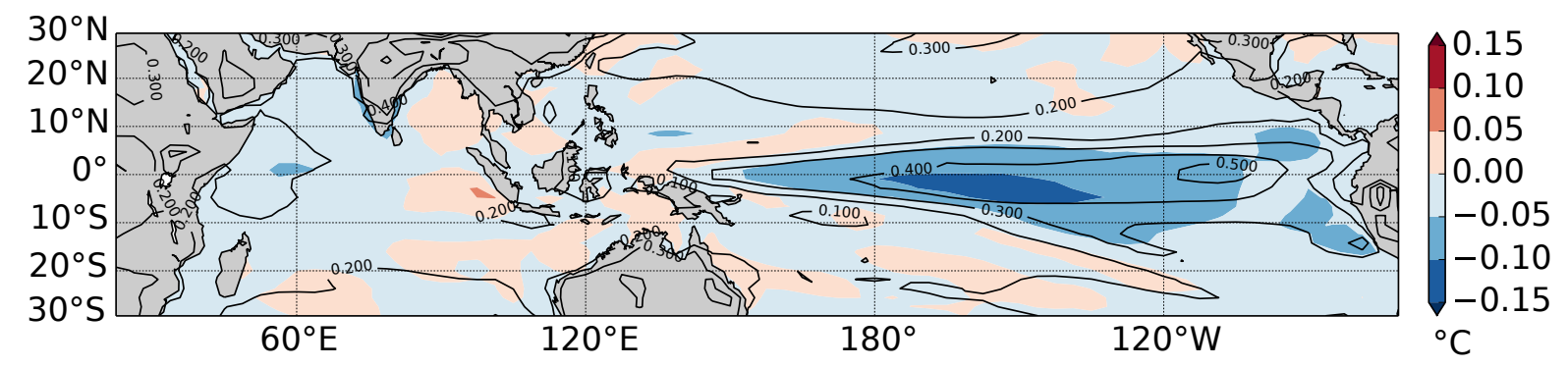

Fig. 4. MH-PI difference in the SST interannual variability. Colors show the MH-PI difference in the standard deviation (StD) of SSTs filtered on the ENSO-frequency band (2-8 years) $\left({ }^{\circ} \mathrm{C}\right)$. Contours show the PI StD of SSTs filtered on the ENSO-frequency band. The ENSO-frequency filtering is computed using a Hanning pass-band filter.

Table 1. Niño3 and Niño3.4 index (standard deviation of monthly SST in the corresponding region) for the MH and the PI, from IPSL-CM5A and from the PMIP3 ensemble (PMIP3 average)

\begin{tabular}{lccccc}
\hline & \multicolumn{2}{c}{ PI } & & \multicolumn{2}{c}{ MH } \\
\cline { 2 - 3 } \cline { 5 - 6 } & IPSL-CM5A & PMIP3 $^{\mathrm{a}}$ & & IPSL-CM5A & PMIP3 $^{\mathrm{a}}$ \\
\hline Niño3 & 0.978 & 0.794 & & 0.767 & 0.753 \\
Niño3.4 & 0.817 & 0.840 & & 0.601 & 0.795 \\
\hline
\end{tabular}

a Values from An and Choi (2013)

Following Saint-Lu et al (2015), El Niño years are identified using a threshold on the SST anomaly over the Niño3 box averaged from November to March (NDJFM). The threshold is calibrated on the PI experiment, and is defined as the standard deviation of the NDJFM-Niño3 SST anomaly multiplied by 1.2. A year is identified as an El Niño year when its NDJFM-Niño3 SST anomaly is above this threshold. This corresponds to moderate-to-large El Niño events, with a strong SST footprint in the eastern Pacific. According to Karamperidou et al (2015), ENSO reduction in the MH is due to changes in eastern Pacific (EP)-type El Niño events, meaning that our threshold is relevant to address MH ENSO changes. The number of selected events is smaller in the $\mathrm{MH}$ than in the PI, with an average of 8.5 events per 100 years in the MH and 12.5 in the PI (i.e. one event every 11.5 years in the MH on average, versus one event every 8 years in the PI).

\section{Energetic budget in the pre-industrial experiment}

\subsection{Mean state energetics}

Horizontal energy transports considered in the following correspond either to the atmospheric energy transports, vertically integrated through the atmospheric column, or to the total energy transports integrated through the ocean-atmosphere column.

In an atmospheric column, the excess or deficit of energy is given by the atmospheric diabatic heating Q:

$$
Q=\operatorname{Rad}_{\mathrm{TOA}}+F_{S}
$$

where $\operatorname{Rad}_{\mathrm{TOA}}$ is the TOA net radiative flux (positive downward), and $F_{S}$ is the total net surface flux (positive upward), including the net radiative flux, the latent heat flux and the sensible heat flux. At equilibrium, $\mathrm{Q}$ is equal to the horizontal divergence of atmospheric moist static energy. The PI long-term mean of $\operatorname{Rad}_{\text {TOA }}$ (Fig. 5) shows that the whole tropical band receives more energy than high latitudes.

\footnotetext{
${ }^{1} \mathrm{Niño} 3=150^{\circ} \mathrm{W}-90^{\circ} \mathrm{W}, 5^{\circ} \mathrm{N}-5^{\circ} \mathrm{S}$; Niño $3.4=170^{\circ} \mathrm{W}-120^{\circ} \mathrm{W}, 5^{\circ} \mathrm{N}-5^{\circ} \mathrm{S}$
} 


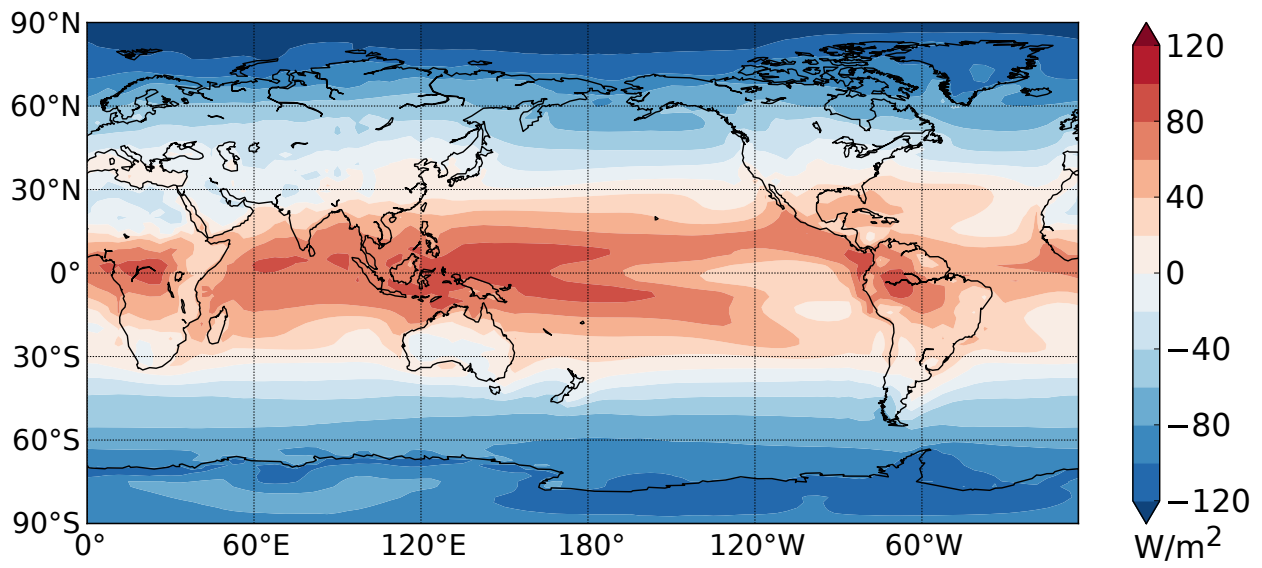

Fig. 5. PI long-term mean $\operatorname{Rad}_{\text {TOA }}$ (positive downward, $\mathrm{W} / \mathrm{m}^{2}$ ).

We consider the atmospheric moist static energy (MSE), combining the dry static energy (heat plus potential energy) and the latent energy:

$$
M S E=C_{P} T+g z+L q
$$

where $C_{P}$ is the specific heat of air at constant pressure, $T$ is the air temperature, $g$ is the gravitational acceleration, $z$ is the altitude, $L$ is the latent heat of condensation and $q$ is the specific humidity.

The MSE horizontal transport $\left(\vec{F}_{M S E}\right)$ is computed as the divergent component of the MSE horizontal flux. The long-term mean $\vec{F}_{M S E}$ is shown in Fig. 6 for the PI. The global reservoir of MSE is over the warm pool, one of the regions receiving the most energy from the TOA (Fig. 5). Energy is exported from this reservoir to the rest of the globe via Hadley and Walker circulations. The order of magnitude obtained with the IPSL-CM5A-LR simulation is the same than that estimated from reanalyses (see Mayer and Haimberger (2012)).

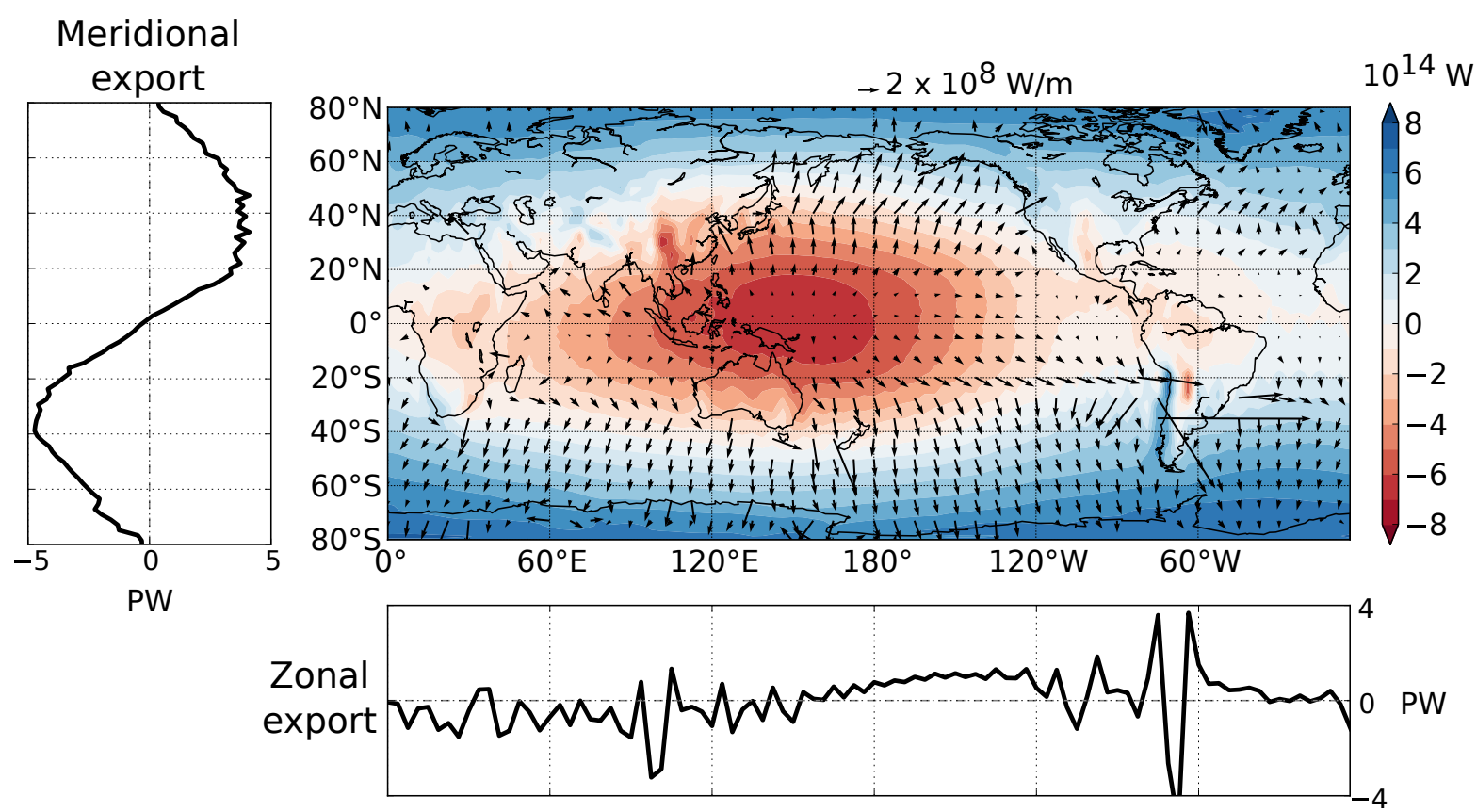

Fig. 6. PI long-term mean MSE transport. The map shows the MSE transport $F_{M S E}$, vertically integrated (arrows, $\mathrm{W} / \mathrm{m}$ ), and the MSE potentials (colors, W), of which the horizontal gradient is equal to $F_{M S E}$ (arrows). Continents are masked because of the too noisy continental signal. Left panel: zonal integration of the meridional component of $F_{M S E}$ $(\mathrm{PW})$. Bottom panel: meridional integration (between $80^{\circ} \mathrm{S}$ and $80^{\circ} \mathrm{N}$ ) of the zonal component of $F_{M S E}(\mathrm{PW})$. Values over land are taken into account in zonal and meridional integrations.

In an ocean-atmosphere column at equilibrium, the annual mean $\operatorname{Rad}_{\mathrm{TOA}}$ is balanced by the divergence of the MSE horizontal export out of the atmospheric column $\left(\vec{\nabla} \cdot \vec{F}_{M S E}\right)$ and the divergence of the ocean 
energy horizontal export out of the oceanic column $\left(\vec{\nabla} \cdot \vec{F}_{O}\right)$ :

$$
\operatorname{Rad}_{\mathrm{TOA}}=\vec{\nabla} \cdot \vec{F}_{M S E}+\vec{\nabla} \cdot \vec{F}_{O}
$$

For the sake of simplicity, arrows indicating vectors are dropped in the following. Globally averaged, the mean value of $\operatorname{Rad}_{\mathrm{TOA}}$ is null because the energy budget of the Earth is balanced. Regions where $\operatorname{Rad}_{\text {TOA }}$ is positive (negative) correspond to sources (sinks) of energy for the ocean-atmosphere system. The long-term mean $\operatorname{Rad}_{\text {TOA }}$ of the PI (Fig. 5) shows that energy transports diverge from the tropics (the source) and converge into high latitudes (the sinks).

\subsection{El Niño energetics}

In this section, energy exchanges associated with El Niño are described for the PI simulation. We build an El Niño composite averaging all the selected El Niño events (selected as described in section 2.3). It represents a "typical" El Niño event. For this El Niño composite, we consider the anomaly (relative to the mean annual cycle) averaged from July to June. This period is chosen because taking the whole year that encompasses the El Niño peak is consistent regarding energetic budgets.

El Niño is associated with cooling and thermocline shoaling in the west, warming and thermocline deepening in the east. The ocean heat content (OHC) anomaly associated with the El Niño composite is thus negative in the western Pacific warm pool and positive in the eastern Pacific (Fig. 7), consistent with observations (Hasegawa and Hanawa, 2003). The surface waters cool in the warm pool and warm in the eastern Pacific, transferring heat from the ocean to the atmosphere via surface fluxes.

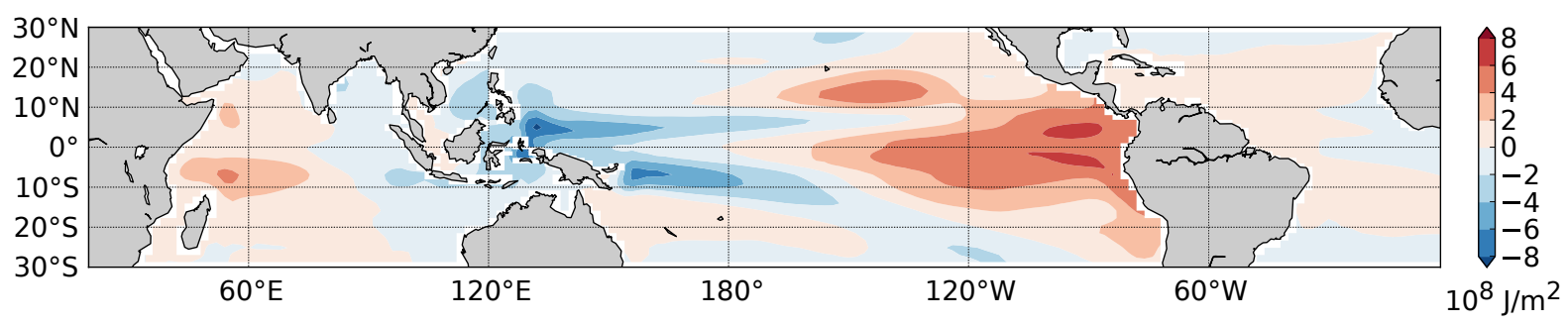

Fig. 7. PI El Niño composite of the Ocean Heat Content anomaly (July-June). OHC is integrated above $300 \mathrm{~m}$ under the surface (units: $\mathrm{J} / \mathrm{m}^{2}$ ).

The El Niño composite of the $F_{M S E}$ anomaly shows that MSE is exported from the whole Pacific area during El Niño events (Fig. 8). This energy is exported both poleward (as shown by the meridional export) and towards the Indian and Atlantic areas. Anomalous zonal transport towards Indian ocean reaches 0.2 PW. Anomalous poleward export is weaker and reaches 0.1 PW towards the North pole. A similar pattern of El Niño atmospheric energy export was found by Mayer et al (2014) from reanalyses. They also highlighted that the El Niño-related energy redistribution was rather zonal between ocean basins, than meridional between low and high latitudes. The El Niño-related energy redistribution is due to both changes in heat sources and changes in the Hadley/Walker circulations (Oort and Yienger, 1996).

We now consider the atmospheric diabatic heating anomaly ( $\mathrm{Q}$ anomaly) in the CE equatorial Pacific $\left(180^{\circ}-80^{\circ} \mathrm{W}, 5^{\circ} \mathrm{N}-5^{\circ} \mathrm{S}\right)$ associated with the El Niño composite (Fig. 9). The anomalous MSE export from this region is maximal (Fig. 8), consistent with the anomalous atmospheric heat excess (i.e. positive Q anomaly) shown in Fig. 9 (left). The decomposition of this atmospheric heating into each heat flux anomaly (Fig. 9, left) shows that it mainly comes from: 1) anomalous latent heat flux at the surface, meaning that oceanic heating brings heat to the atmosphere via evaporative cooling, 2) anomalous longwave (LW) radiations. The latter is decomposed as the sum of the cloud radiative forcing (CRF) and the clear-sky term (Fig. 9, right). This decomposition allows us to understand how anomalous LW radiations contribute to heat the atmospheric column. First, as shown by the latent heat flux contribution, oceanic heating brings latent heat and humidity to the atmosphere via evaporative cooling. The atmospheric water vapor amount is increased and convective activity is enhanced. In addition, convective clouds converge into the eastern equatorial Pacific. As a result, the atmosphere traps more LW radiations. At the TOA, the CRF thus reduces outgoing longwave radiations, as shown by Fig. 10b, explaining its positive contribution in Fig. 9. This is in agreement with reanalyses (Trenberth et al, 2002). On the other hand, due to atmospheric heating and water vapor increase, the atmosphere emits more LW radiations downward, warming the surface, explaining the negative contribution of the net clear-sky LW anomaly at the surface. However, the latter is not sufficient to balance the CRF on net LW radiations at the surface, due to low-level cloud cover change. Fig 10a suggests that the low-level cloud cover, prevailing 


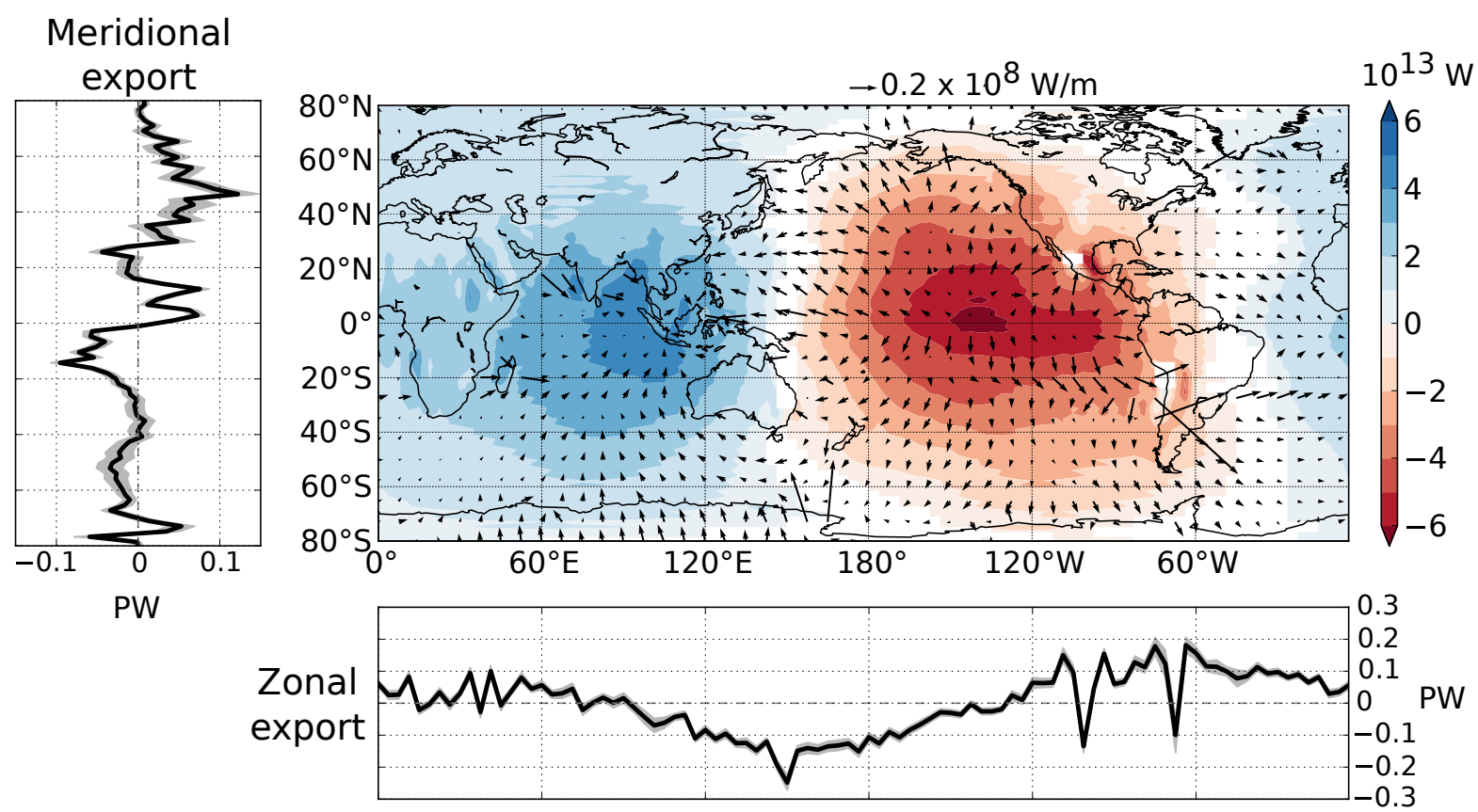

Fig. 8. PI El Niño composite of MSE transport anomaly (July-June). The map shows the El Niño composite of MSE transport (vertically integrated, $F_{M S E}$ ) anomaly (arrows, W/m), and of MSE potentials anomaly (colors, W). The latter is drawn only where significantly different from zero (i.e. where the $90 \%$ confidence interval estimated from bootstrap resampling - see Methods - does not contain zero). Continents are masked because of the too noisy continental signal. Left panel: zonal integration of the meridional component of the $F_{M S E}$ anomaly (PW). Bottom panel: meridional integration (between $80^{\circ} \mathrm{S}$ and $80^{\circ} \mathrm{N}$ ) of the zonal component of the $F_{M S E}$ anomaly (PW). Incertitude ranges on left and bottom panels give the $90 \%$ confidence intervals, estimated from bootstrap resampling (see Methods). Values over land are taken into account in zonal and meridional integrations.

in the eastern Pacific, is reduced during El Niño events in the IPSL-CM5A-LR model. This is consistent with reduced subsidence over this region due to reduced Walker circulation. Since low-level clouds have a strong albedo effect, less SW radiations are reflected to space and more enter the surface, explaining the positive and negative contributions of the CRF on net SW radiations at the TOA and at the surface, respectively (Fig. 9). The low-level cloud cover reduction also has a strong effect on LW radiations at the surface. Since clouds are low-level, they emit LW radiations at a temperature which is relatively close to the surface temperature. A reduction in the low-level cloud cover directly reduces the incoming LW radiations at the surface, indirectly contributing to heat the atmosphere. Fig 10c shows that the anomalous CRF on net LW radiations at the surface is indeed positive (i.e. contributes to heat the atmosphere) in the whole CE equatorial Pacific, explaining its positive contribution in Fig. 9. In other words, low-level clouds are reduced in the whole box, allowing more LW radiations emitted by the surface to enter the atmosphere. Meanwhile, convective clouds are increased in the western part of the box, trapping more LW radiations coming from the surface. Combining the two results in atmospheric heating.

Previous studies using observations and reanalysis showed that the predominant source of atmospheric diabatic heating associated with $\mathrm{El} \mathrm{Niño} \mathrm{is} \mathrm{the} \mathrm{latent} \mathrm{heat} \mathrm{flux} \mathrm{resulting} \mathrm{from} \mathrm{surface} \mathrm{evaporative} \mathrm{cooling}$ (Trenberth et al, 2002; Mayer and Haimberger, 2012). The IPSL-CM5A-LR model may overestimate the role of LW radiations at the surface. Most of the CMIP5 coupled models actually suffer from cloud feedback biases (Li et al, 2015). In particular, high clouds and humidity associated with El Niño are underestimated in the IPSL-CM5A-LR model, and cloud structures are shifted westward. While the model exhibit a reduction in the low-level cloud cover in the eastern Pacific, observations rather exhibit an increase in the total cloud fraction over the whole CE Pacific, due to increased convection during El Niño (Li et al, 2015).

These changes in cloud cover are equivalent to positive $\operatorname{Rad}_{\mathrm{TOA}}$ anomaly over the equatorial Pacific (contributions of radiative fluxes at the TOA are positive in Fig. 9), meaning that the whole oceanatmosphere column is in energy excess during El Niño years (more energy entering than leaving). This is not in agreement with observations, that show a relatively small but negative Rad $_{\mathrm{TOA}}$ anomaly in the tropical Pacific associated with El Niño (Mayer et al, 2014). This is interpreted as the radiation to space of part of the atmospheric energy excess coming from the oceanic discharge. In the IPSL-CM5A-LR model, cloud feedback biases may reverse the sign of the Rad ${ }_{T O A}$ anomaly. Hence, atmospheric energy excess is not partly radiated to space as in the observations, but may be additionally amplified by cloud 

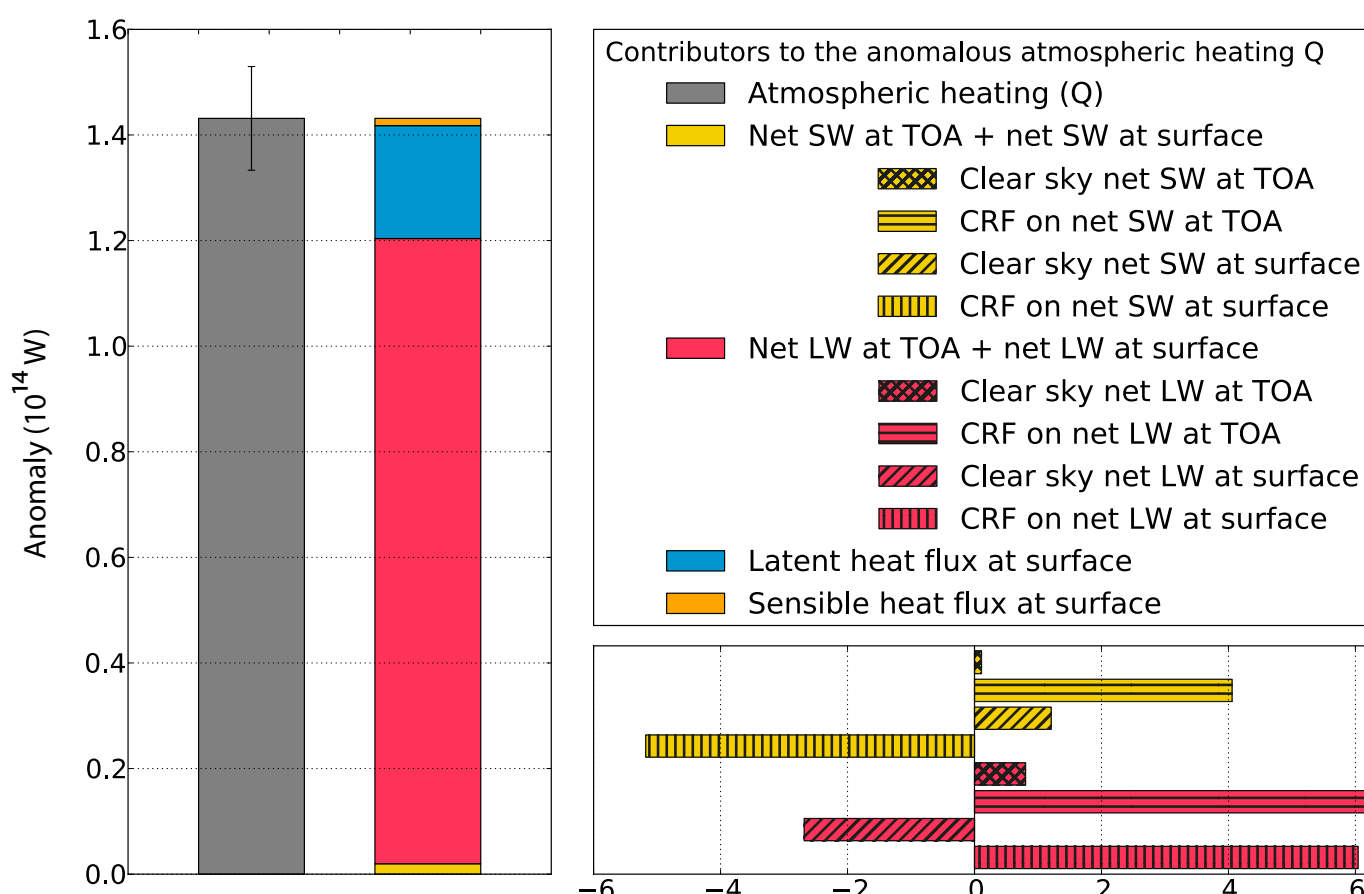

Latent heat flux at surface

Sensible heat flux at surface

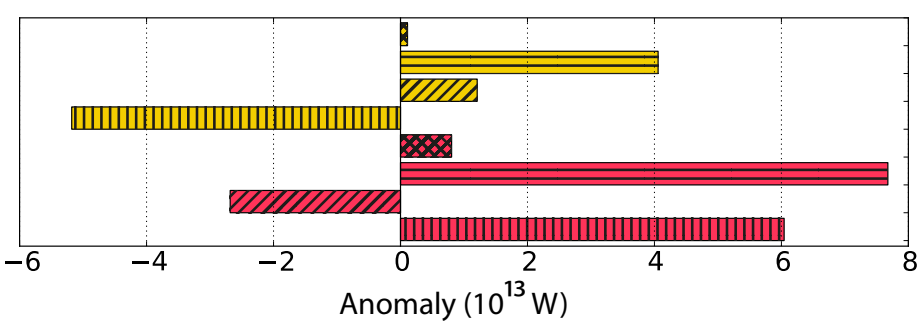

Fig. 9. PI El Nino composite of the atmospheric heating (Q) anomaly (July-June), and its decomposition into the anomalous surface energy fluxes (positive upward) and TOA fluxes (positive downward), horizontally integrated over the central-eastern (CE) equatorial Pacific $\left(\mathbf{1 8 0}^{\circ}-\mathbf{8 0}^{\circ} \mathbf{W}-5^{\circ} \mathbf{N}-5^{\circ} \mathrm{S}\right)$. All fluxes are positive when entering the atmosphere. Left: Q anomaly and its decomposition into sensible heat (orange), latent heat (blue), LW (magenta) and SW (yellow) fluxes (W). Error bar gives the $90 \%$ confidence interval, estimated from bootstrap resampling (see Methods). Bottom-right: SW and LW components, distinguishing TOA and surface fluxes, decomposed into the CRF and the clear-sky term.

feedback processes.

To summarize, in the IPSL-CM5A-LR PI simulation, the eastern Pacific warming brings heat to the atmosphere via latent heat fluxes and radiative LW fluxes, which is amplified by LW cloud feedback. This atmospheric energy is then exported from the whole Pacific, mainly towards Indian and Atlantic oceans areas (Fig. 8).

The El Niño Rad ${ }_{\text {TOA }}$ anomalies, the warm pool discharge and the MSE export show that El Niño events contribute to the global energy redistribution, by exporting part of the energy excess out of the tropical Pacific.

\section{Energetic changes in the mid-Holocene experiment}

\subsection{Mean state changes}

In the $\mathrm{MH}$, the stronger thermocline tilt (see Sect. 2.2 and Fig. 3) results in larger $\mathrm{OHC}$ in the warm pool, compared to the PI (Fig. 11, top). However, in average OHC is reduced when considering the whole tropical band (Fig. 11, top). This is consistent with reduced tropical insolation and the associated tropical cooling.

Insolation forcing in the MH brings annually less energy to the tropics and more to the high latitudes. Fig. 11 (bottom) shows the mean $\operatorname{Rad}_{\mathrm{TOA}}$ response to this forcing in the tropics. Black curve indicates the $\mathrm{MH}$ radiative forcing as defined by Braconnot et al (2000), i.e. the change in the net SW radiation at TOA when considering no change in the planetary albedo. As pointed out by Mantsis et al (2011), when integrated zonally this radiative forcing gives the "theoretical" change in $\operatorname{Rad}_{\mathrm{TOA}}$, i.e. the change that would be obtained as a direct response to the change in the incoming solar radiation. Here, the MH radiative forcing is negative in the tropics because annual mean insolation is reduced. The tropical band receives less solar energy than in the PI; then if we consider that it emits as much energy to space (i.e. considering the theoretical change in $\operatorname{Rad}_{\mathrm{TOA}}$ ) it necessarily implies that it exports less energy poleward. 
a) El Nino composite anomaly of SW CRF at TOA (PI)

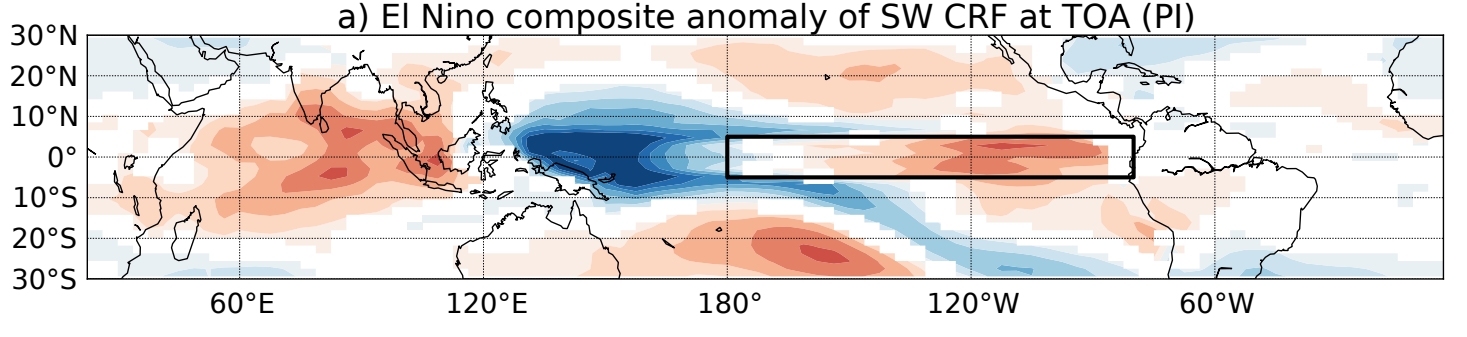

b) El Nino composite anomaly of LW CRF at TOA (PI)

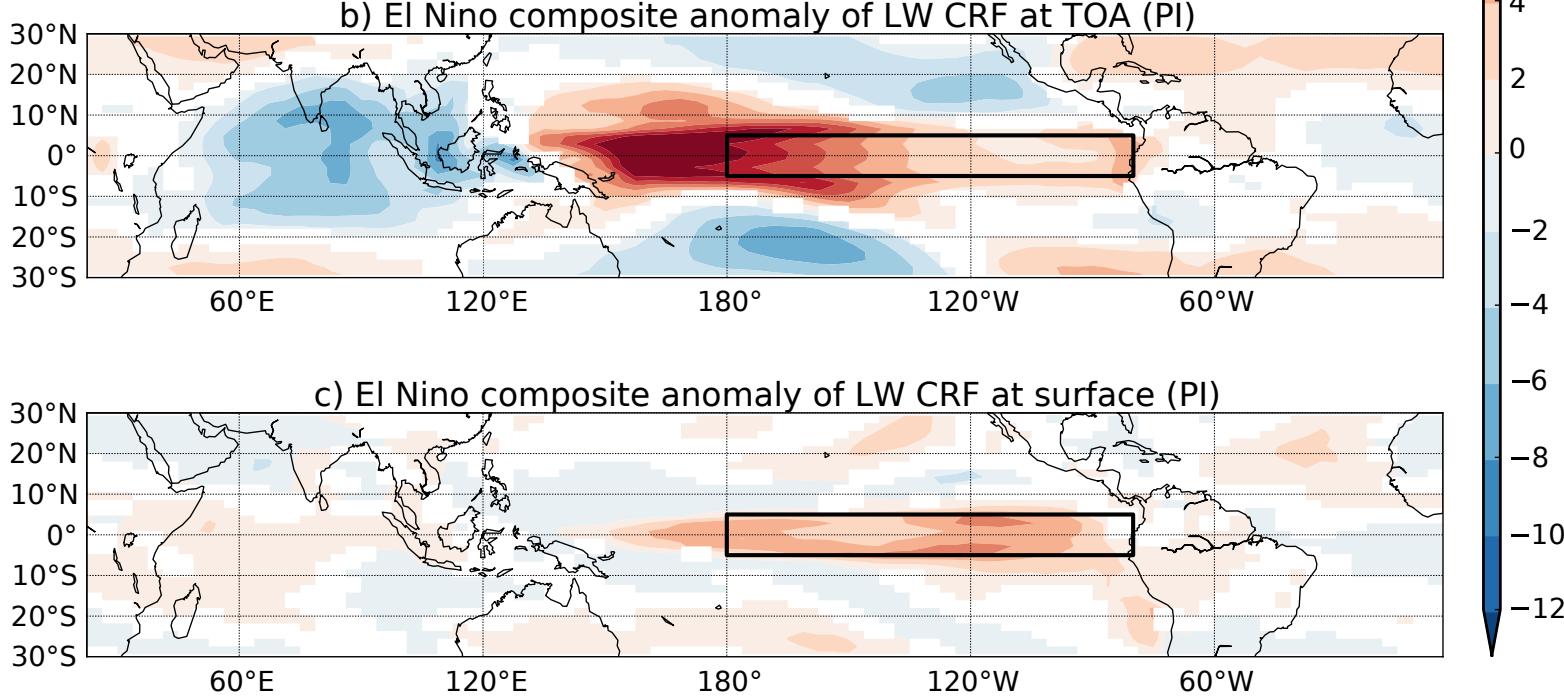

Fig. 10. PI El Niño composite of various Cloud Radiative Forcings (CRFs, W $/ \mathbf{m}^{2}$ ) anomalies (July-June). All the CRFs are defined here positive when more radiative flux enters the atmosphere in cloudy conditions. a) CRF on net SW radiations at the TOA (difference between the net downward solar radiations at TOA with and without clouds). Its global value is always negative because solar radiations are reflected to space by clouds. Inside the rectangle showing the CE equatorial Pacific region, the El Niño anomaly is positive, which means less clouds reflecting solar radiations. This suggests a reduced low-level cloud cover b) CRF on net LW radiations at the TOA (difference between the net downward LW flux at TOA with and without clouds). Its global value is always positive because LW radiations are trapped by clouds. Inside the CE equatorial Pacific, the El Niño anomaly is positive, which means more clouds trapping LW radiations. This shows an increased convective cloud cover. c) CRF on net LW radiations at the surface (difference between the net upward LW radiations at the surface with and without clouds). Its global value is always negative because LW radiations emitted by clouds are absorbed by the surface. Inside the CE equatorial Pacific, the El Niño anomaly is positive, which means less clouds emitting LW radiations directly to the surface. Values are drawn only where significantly different from zero (i.e. where the $90 \%$ confidence interval estimated from bootstrap resampling - see Methods - does not contain zero). 

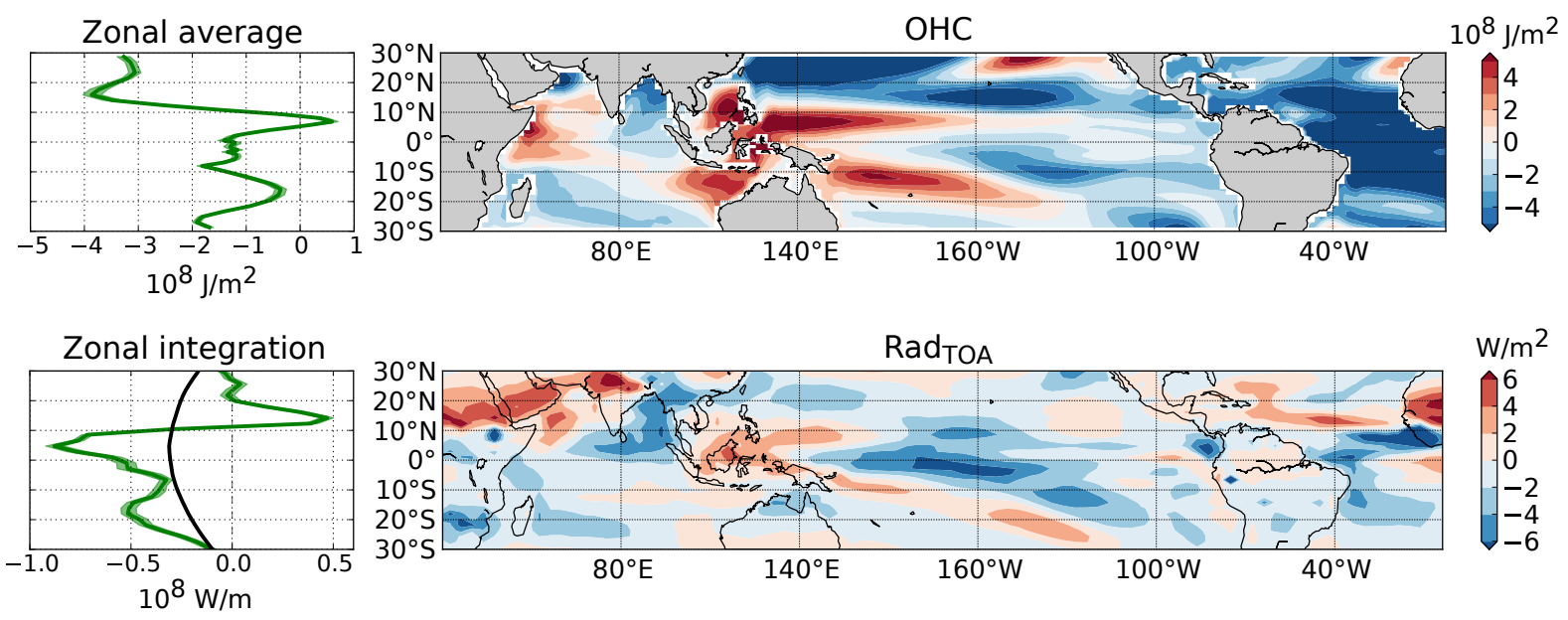

Fig. 11. MH-PI long-term mean differences in OHC and $\mathbf{R a d}_{\text {TOA }}$. Top: MH-PI difference in the long-term mean $\mathrm{OHC}\left(\mathrm{J} / \mathrm{m}^{2}\right)$ in the tropical band (right panel), and its zonal average $\left(\mathrm{J} / \mathrm{m}^{2}\right)$ (left panel). Bottom: MH-PI difference in the long-term mean $\operatorname{Rad}_{\mathrm{TOA}}\left(\mathrm{W} / \mathrm{m}^{2}\right)$ in the tropical band (right panel), and its zonal integration (green curve, $\left.\mathrm{W} / \mathrm{m}\right)(\mathrm{left}$ panel). The black curve gives the "MH radiative forcing", or "theoretical" change, as defined in the text. Incertitude ranges on left panel give the $90 \%$ confidence intervals, estimated from bootstrap resampling (see Methods).

In other words, the theoretical response of the tropics to the $\mathrm{MH}$ insolation forcing is to export less energy, as a direct consequence of the fact that it receives less energy.

Comparing this theoretical change in $\operatorname{Rad}_{\mathrm{TOA}}$ (i.e. the radiative forcing) to the actual one (green curve) shows that the $\operatorname{Rad}_{T O A}$ reduction is actually larger than the radiative forcing between $30^{\circ} \mathrm{S}$ and $10^{\circ} \mathrm{N}$. Thus, this region, which receives less energy in the $\mathrm{MH}$, also emits more energy to space, meaning that it exports even less energy poleward. Internal processes (feedbacks, albedo, large-scale circulation, etc.) amplify the theoretical response to the $\mathrm{MH}$ insolation forcing, that is the reduction of poleward export of energy out of the tropics.

However, north of $10^{\circ} \mathrm{N}, \operatorname{Rad}_{\mathrm{TOA}}$ is less reduced than the radiative forcing, since it is in fact increased, with a positive peak at $15^{\circ} \mathrm{N}$. It is consistent with the strong positive signal in North Africa and southwestern Asia. This area is a sink of energy coming from space in long-term mean, as shown by Fig. 5. In the $\mathrm{MH}$, this area receives less energy (since the radiative forcing given by the black curve is negative), emits even less energy to space (since the $\operatorname{Rad}_{\mathrm{TOA}}$ change given by the green curve is positive), meaning that it imports less energy. It could be the signature of the intensified summer monsoon flow.

Processes amplifying the reduction of energy export out of the tropics are actually mainly located in the tropical Pacific. Identifying these processes (that can be associated with feedbacks, albedo, largescale circulation, etc.) is beyond the scope of this paper, but it is worth noting that cloud feedback biases mentioned in section 3.2 could also affect the model response to the $\mathrm{MH}$ radiative forcing. Further investigations would be necessary to understand the impact of this bias.

Fig. 12 shows the long-term mean changes in MSE transport, in the MH compared to the PI. The mean MSE export out of the tropical Pacific is reduced. This is consistent with $\mathrm{OHC}$ reduction and tropical SST cooling (see Sect. 2.2 and Fig. 2), reducing ocean heat available for the atmosphere. This is also consistent with reduced poleward export of energy out of the tropics. Changes in MSE zonal export are noisy but coherent features can be seen: anomalous eastward transport from the Indian ocean towards the Pacific and westward transport from the Atlantic. This can also be interpreted as less energy being transferred into the Indian and Atlantic from the Pacific, compared to PI (Fig. 6). Changes in the meridional export show that MSE poleward export is reduced in the MH. This is again consistent with reduced poleward export of energy out of the tropics, which is not only due to reduced insolation but is further amplified by internal processes, as shown previously (Fig. 11, bottom).

From these results it appears that in the MH, the role of energy source played by the tropical Pacific is reduced. On the contrary, the area over Europe, northern Africa and western Asia, impacted by summer warming and boreal monsoon, exports more MSE (or imports less).

\subsection{El Niño changes}

Figure 13a shows the evolution of OHC in the warm pool over the 3 years around the peak of the El Niño composite, in the $\mathrm{MH}$ and in the PI. The two experiments exhibit a negative OHC anomaly associated with El Niño, as already seen in Fig. 7 for the PI, in the warm pool region. This warm pool discharge is 


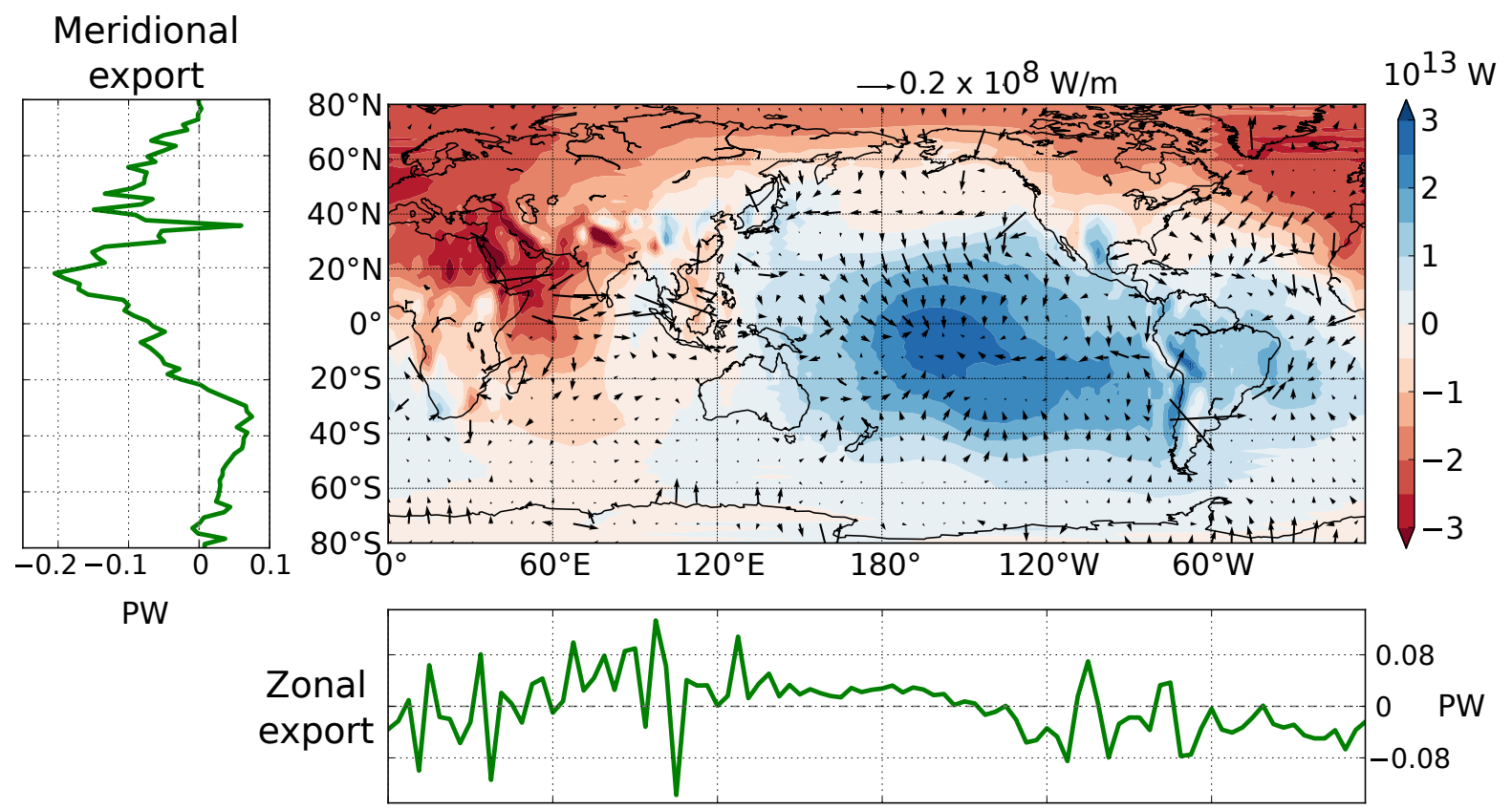

Fig. 12. MH-PI long-term mean difference in MSE transport. The map shows the MH-PI long-term mean difference in MSE transport, vertically integrated $\left(F_{M S E}\right)$ (arrows, W/m), and in MSE potentials (colors, W). Continents are masked because of the too noisy continental signal. Left panel: zonal integration of the MH-PI difference in the meridional component of the $F_{M S E}$ long-term mean (PW). Bottom panel: meridional integration (between $80^{\circ} \mathrm{S}$ and $80^{\circ} \mathrm{N}$ ) of the MH-PI difference in the zonal component of the $F_{M S E}$ long-term mean (PW). Values over land are taken into account in zonal and meridional integrations.

associated with thermocline rising in this region, and does not refer to the Jin's oscillator discharge (Jin, 1997) that deals with Sverdrup transport at $5^{\circ} \mathrm{N}$ and $5^{\circ} \mathrm{S}$. The amplitude of the El Niño-related warm pool discharge in the $\mathrm{MH}$ is not significantly different from the PI, statistically, but appears smaller and its duration is shorter (23 months in the $\mathrm{MH}$ against 25 in the PI). The discharge starts about 2 to 3 months later, consistent with previous studies (Zheng et al, 2008; Luan et al, 2012). Smaller warm pool heat discharge would be consistent with ENSO reduction in the MH. It is worth noting that while the warm pool heat discharge is equal or smaller, more heat is contained in average in the warm pool (Fig. 11, top).
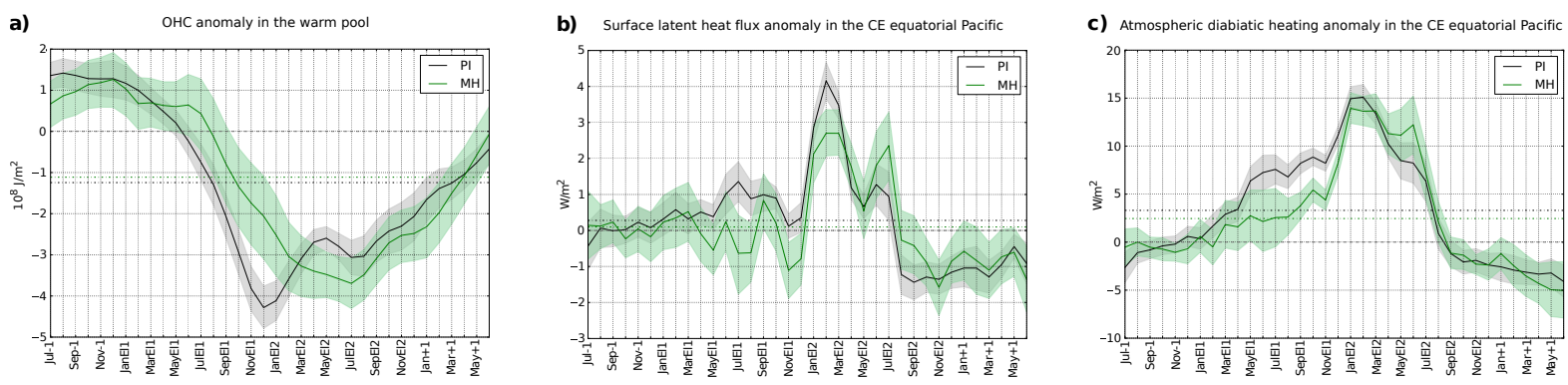

Fig. 13. MH and PI El Niño composites of the Pacific discharge. Through the 3 years around the El Niño peak, El Niño composite of: a) OHC monthly anomalies $\left(\mathrm{J} / \mathrm{m}^{2}\right)$, averaged over the "warm pool" $\left(100^{\circ} \mathrm{E}-170^{\circ} \mathrm{E}, 10^{\circ} \mathrm{N}-10^{\circ} \mathrm{S}\right)$. $\mathrm{OHC}$ is integrated over $300 \mathrm{~m}$ under the surface; b) surface latent heat flux monthly anomalies $\left(\mathrm{W} / \mathrm{m}^{2}\right)$, averaged over the central-eastern $(\mathrm{CE})$ equatorial Pacific $\left(180^{\circ} \mathrm{E}-80^{\circ} \mathrm{W}, 5^{\circ} \mathrm{N}-5^{\circ} \mathrm{S}\right)$; c) Q monthly anomalies $\left(\mathrm{W} / \mathrm{m}^{2}\right)$, averaged over the CE equatorial Pacific. The year before the El Niño is indicated by -1 (Month-1), the first year of the El Niño by El1, the second year by El 2 and the year after by +1 . The peak is between the months NovEl1 and MarEl2. The dashed black and green lines give the mean over the 3 years, for the PI and the MH respectively. Incertitude ranges give the $90 \%$ confidence intervals, estimated from bootstrap resampling (see Methods).

A smaller warm pool heat discharge would imply that the atmosphere takes less energy from the ocean during El Niño. This is confirmed by the evolution of latent heat flux in the CE Pacific over the 3 years around the peak of the El Niño composite (Fig. 13b). At the peak of the event, the latent heat flux anomaly is indeed smaller in the MH than in the PI. From the summer season of the second year of the event, the latent heat flux anomaly becomes greater in the $\mathrm{MH}$, which is consistent with delayed development of events. In average over the three years, the latent heat flux anomaly is smaller in the $\mathrm{MH}$ 
than in the PI.

Since the atmosphere takes less energy from the ocean during El Niño, atmospheric diabatic heating is reduced. Over the 3 years around the peak of the El Niño composite (Fig. 13c), atmospheric diabatic heating in the CE Pacific is smaller in the MH than in the PI. During the summer season of the second year, anomalous atmospheric heating becomes greater in the $\mathrm{MH}$, consistent with latent heat flux and OHC anomalies (Fig. 13a et b).

These results show that in the MH, less energy is discharged from the ocean to the atmosphere. As a consequence, the El Niño-related export of MSE out of the tropical Pacific is expected to be reduced. Figure 14 compares MH and PI distributions of the El Niño composite of MSE potential anomaly in the central Pacific (at $0^{\circ} \mathrm{N}, 140^{\circ} \mathrm{W}$, where the El Niño composite of MSE potential is maximal - see Fig. 8). El Niño signature on MSE potential in this region reflects the diversity of El Nino events, but in the MH most events exhibit a reduced MSE potential anomaly (in absolute values). Based on these distributions, we show on Fig. 15 the difference map between MH and PI El Niño composites of MSE potentials anomaly, drawn only where the MH composite (mean of the distribution) is outside the $50 \%$ confidence interval of the PI composite. In the MH, less MSE is exported out of the central Pacific during El Niño (positive MH-PI difference in the central Pacific meaning less divergence). A reduction in the anomalous poleward export can be seen, especially in the southward export. There is no substantial change in the zonal export.

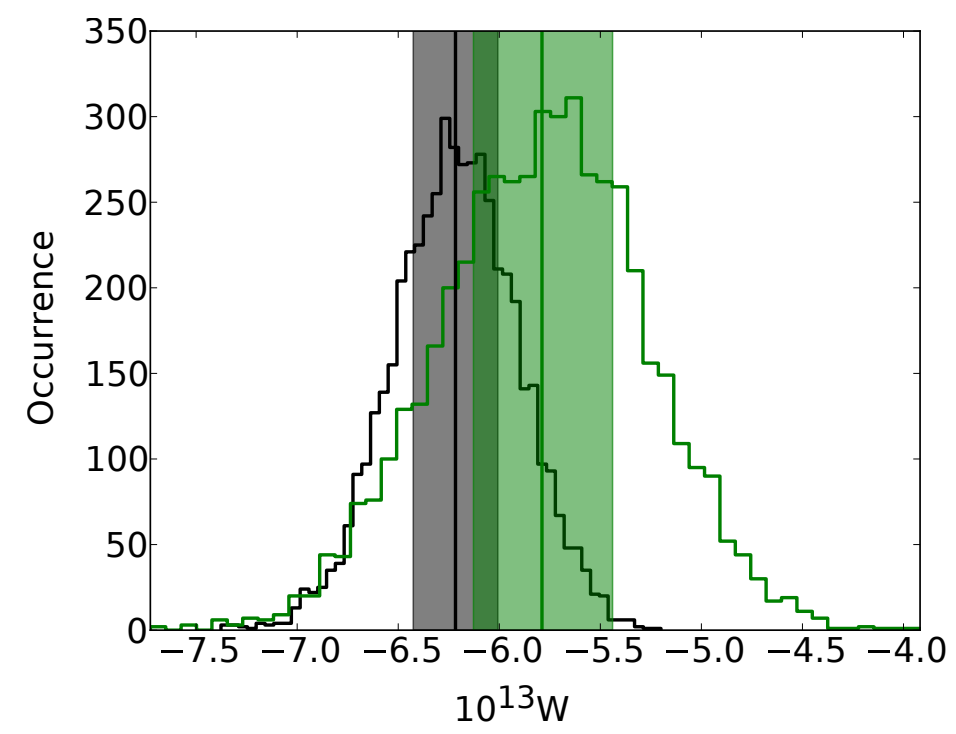

Fig. 14. PI and MH estimations of the El Niño composite of MSE potential anomaly in the central Pacific (July-June). PI (black) and MH (green) distributions of the 5000 estimations (bootstrap resampling-see Methods) of the El Niño composite of MSE potential anomaly in the central Pacific $\left(0^{\circ} \mathrm{N}, 140^{\circ} \mathrm{W}\right.$, i.e. where the El Niño composite of MSE potentials anomaly is maximal-see Fig. 8). Shaded vertical ranges show $50 \%$ intervals.

It is worth pointing out that this result provides indications of large-scale changes in El Niño teleconnections in the $\mathrm{MH}$.

\section{Relative role of El Niño in the Pacific discharge}

Previous section highlights that the El Niño-related Pacific discharge - associated with oceanic discharge, atmospheric diabatic heating and export of MSE in the CE Pacific - is reduced in the MH. This reduced Pacific discharge associated with El Niño is superimposed on the reduced role of energy source played by the tropical Pacific in the MH mean state (see Sect. 4.1) ${ }^{2}$. Is the reduction in the El Niño-related Pacific discharge proportional to the reduction in the mean energy export of the Pacific? In other words, does the fraction of Pacific discharge that is due to El Niño remain equal in the two climates (MH and PI)? Since both amplitude and occurrence of events determine the role of El Niño in the Pacific discharge, this question can only be addressed by considering long-term temporal integrations.

To characterize the Pacific discharge, we rely on four indices: the average of (i) $\operatorname{Rad}_{\mathrm{TOA}}$ over the CE Pacific $\left(\operatorname{Rad}_{\text {TOACE}}\right)$ where $\operatorname{Rad}_{\mathrm{TOA}}$ is positive throughout the $1000 / 500$ years of the simulations, (ii) Q

\footnotetext{
${ }^{2}$ It is worth specifying that the results obtained for the MH long-term mean changes in Sect. 4.1 are similar when considering the mean over the entire simulation or over "neutral" years only, i.e. neither selected as El Niño nor as La Niña with the inverse threshold (not shown).
} 


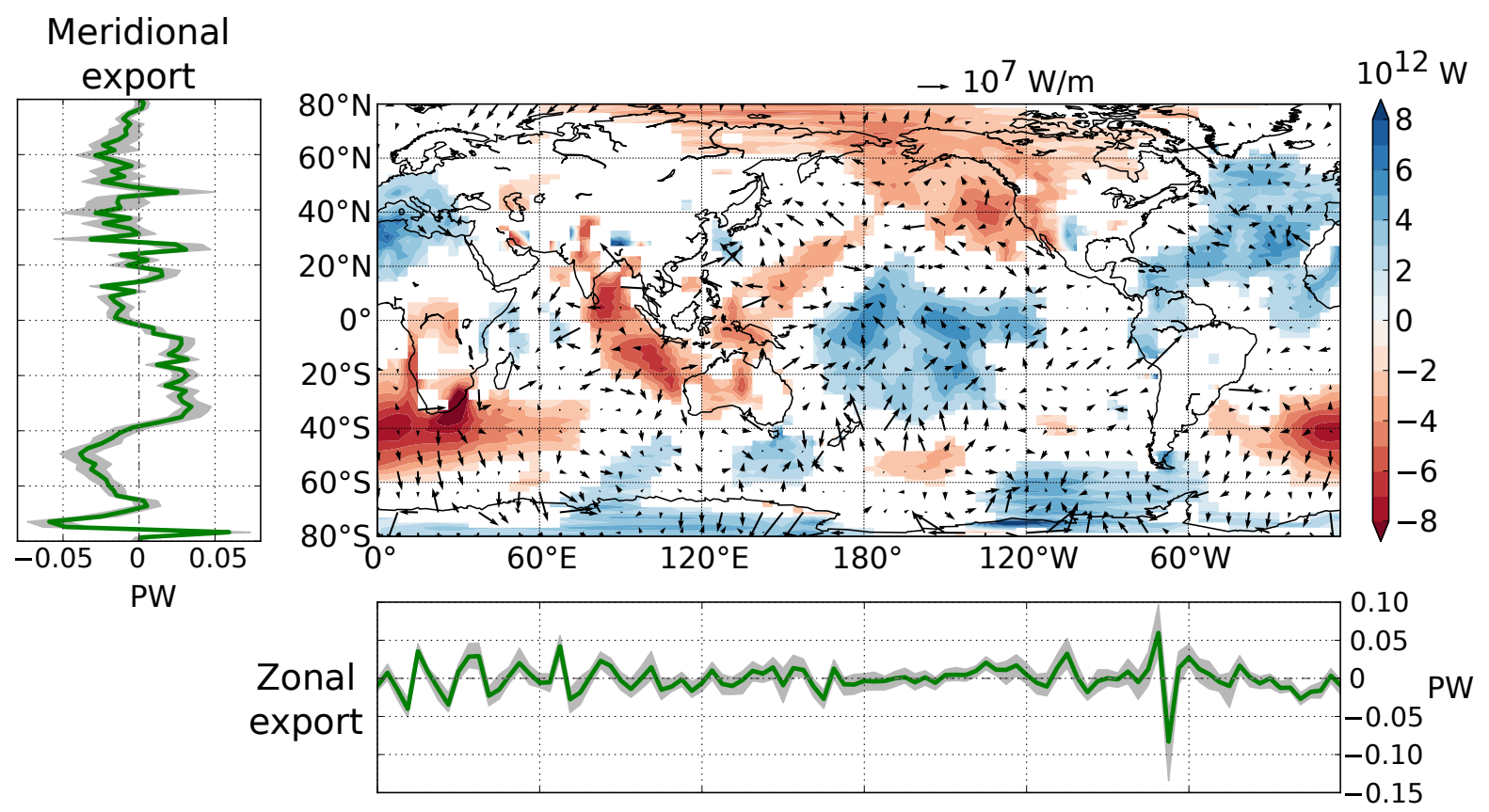

Fig. 15. MH-PI difference in the El Niño composite of MSE transport anomaly (July-June). The map shows the MH-PI difference in the El Niño composite of MSE transport (vertically integrated, $F_{M S E}$ ) anomaly (arrows, W/m), and of MSE potentials anomaly (colors, W). The latter is drawn only where the MH-PI difference is significant (i.e. where the $\mathrm{MH}$ composite is outside the $50 \%$ confidence interval of the PI composite estimated from bootstrap resampling-see Methods). Continents are masked because of the too noisy continental signal. Left panel: zonal integration of MH-PI difference in the meridional component of the $F_{M S E}$ anomaly $(\mathrm{PW})$. Bottom panel: meridional integration (between $80^{\circ} \mathrm{S}$ and $80^{\circ} \mathrm{N}$ ) of the MH-PI difference in the zonal component of the $F_{M S E}$ anomaly (PW). Incertitude ranges on left and bottom panels give the $50 \%$ confidence intervals, estimated from bootstrap resampling (see Methods). Values over land are taken into account in zonal and meridional integrations.

over the eastern Pacific $\left(130^{\circ} \mathrm{W}-90^{\circ} \mathrm{W}-5^{\circ} \mathrm{N}-5^{\circ} \mathrm{S}\right)\left(\mathrm{Q}_{E}\right)$ where $\mathrm{Q}$ is negative throughout the simulations (i.e. this column is an energy sink), (iii) $\mathrm{OHC}$ over the $\mathrm{CE}$ Pacific $\left(\mathrm{OHC}_{C E}\right)$, (iv) OHC over the warm pool region $\left(100^{\circ} \mathrm{E}-170^{\circ} \mathrm{E}-10^{\circ} \mathrm{N}-10^{\circ} \mathrm{S}\right)\left(\mathrm{OHC}_{W P}\right)$. For each variable, we define the "integrated Niño anomaly", which is the El Niño anomaly integrated over every month of every El Niño year of the simulation (taking 12 months around the NDJFM peaks of the El Niño years, as selected in Sect. 2.3). Then we consider the ratio between this integrated Niño anomaly and the "integrated total value" over the 1000 or 500 years of the PI or MH simulation respectively. The latter is the total value integrated over all months of the simulation. This ratio represents the "fraction due to El Niño" for each index $i$, where $i$ refers to $\operatorname{Rad}_{T O A C E}, \mathrm{Q}_{E}, \mathrm{OHC}_{C E}$ or $\mathrm{OHC}_{W P}$ :

$$
\text { Fraction due to } \operatorname{El} \operatorname{Niño}(i)=\frac{\sum_{\text {Niño months }} \operatorname{Anom}(i)}{\sum_{\text {all months }} i}
$$

With this method, we do not only rely on the comparison between MH and PI El Niño composites, but we further take into account the change in the occurrence of events, which also has an impact on the role of El Niño in discharging the tropical Pacific and exporting the energy poleward.

Figure 16a shows the fraction due to El Niño for the four indices in the MH and in the PI, built from the temporal integration described above. In the PI, $2.3 \%$ of ocean-atmosphere heating of the CE Pacific $\left(\operatorname{Rad}_{\text {TOACE}}\right)$ is due to El Niño; $-2.5 \%$ of atmospheric diabatic heating over the eastern Pacific $\left(\mathrm{Q}_{E}\right)$ is due to El Niño (the fraction is negative because this atmospheric column is an energy sink but El Niño heats it); $0.22 \%$ of the $\mathrm{CE}$ Pacific heat content $\left(\mathrm{OHC}_{C E}\right)$ is due to El Niño; such as $-0.16 \%$ of the warm pool heat content $\left(\mathrm{OHC}_{W P}\right)$. It is worth pointing out that the fraction is relatively small for $\mathrm{OHC}_{C E}$ and $\mathrm{OHC}_{W P}$ because the integrated total value (denominator of the fraction) is relatively large given that $\mathrm{OHC}$ is spatially integrated (over $300 \mathrm{~m}$ under the surface).

Note that fractions due to La Niña should have opposite signs, balancing at least partly fractions due to El Niño and resulting in no substantial role of the full ENSO cycle. This is the reason why we only consider the El Niño phase of ENSO (the one associated with the discharge): it allows us to see if there is proportionality between $\mathrm{MH} / \mathrm{PI}$ mean-state changes and $\mathrm{MH} / \mathrm{PI}$ El Niño changes.

In the $\mathrm{MH}$, fractions due to El Niño are 1.3-to-2 times smaller (1.5\% for $\operatorname{Rad}_{\mathrm{TOACE}}$, about $-1.9 \%$ 

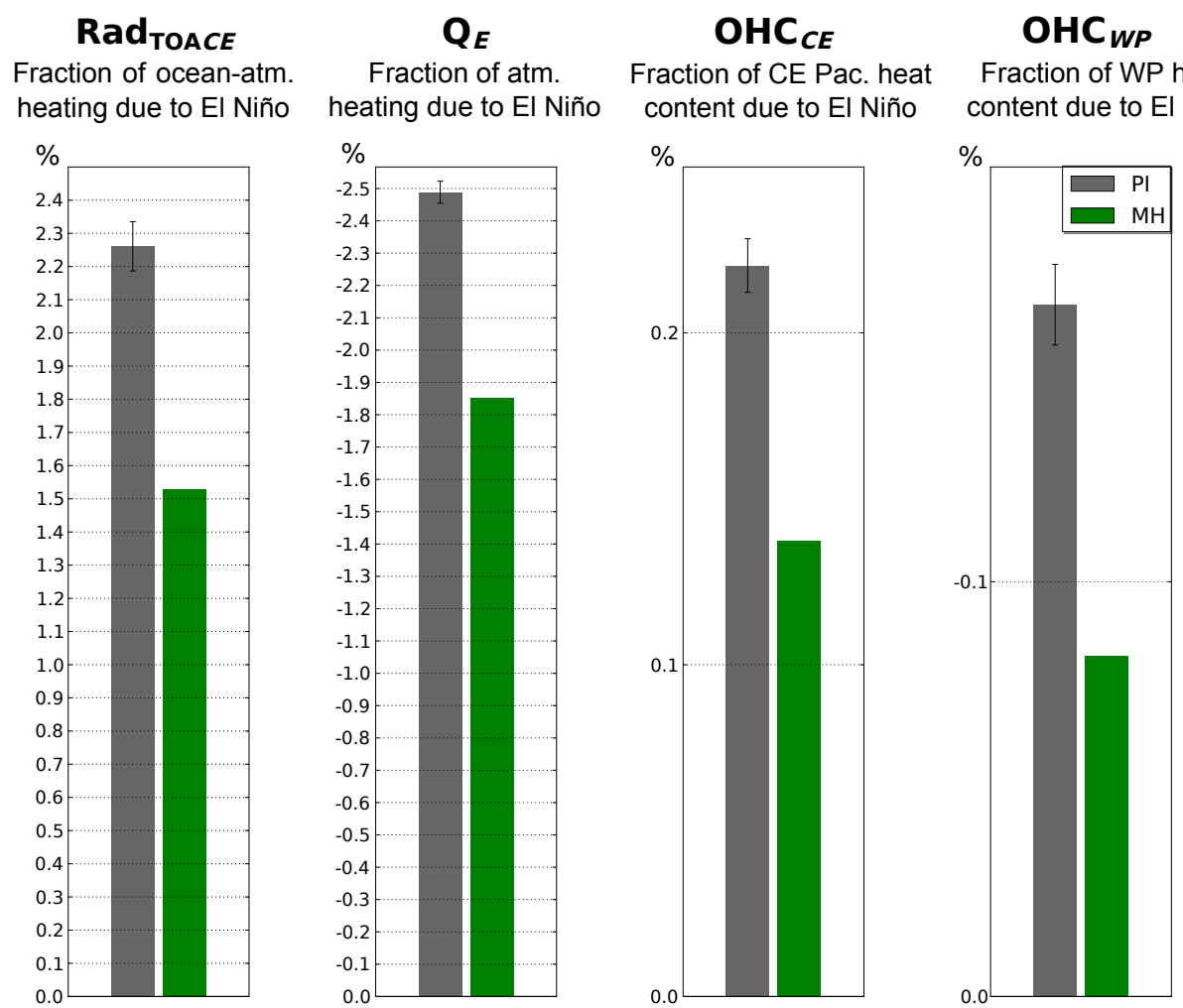

Fig. 16. PI and MH fractions due to El Niño (\%), built from temporal integration as described in the text. Error bars show the range given by two particular cases: when only the first 500 years and only the last 500 years of the PI simulation are considered.

for $\mathrm{Q}_{E}$, about $0.14 \%$ for $\mathrm{OHC}_{C E}$ and about $-0.08 \%$ for $\mathrm{OHC}_{W P}$ ) meaning that the fraction of Pacific discharge that is due to El Niño is smaller. The fact that all the four fractions are equivalently reduced in the $\mathrm{MH}$ gives confidence in this result. We know that in the $\mathrm{MH}$, the mean $\mathrm{OHC}$ in the warm pool is greater (Fig. 11, top), while the El Niño discharge is smaller (see Sect. 4.2), explaining the smaller fraction of warm pool heat content that is due to El Niño. This clearly points out that the change in the warm pool discharge is not proportional to the change in the mean OHC. As a consequence, the fraction of eastern Pacific heat content that is due to El Niño is also reduced, due to the heat transfer eastward. It follows that the fraction of atmospheric diabatic heating that is due to El Niño is reduced, reducing also the fraction of ocean-atmosphere heating due to El Niño.

We now artificially impose the same El Niño occurrence in the two climates (the El Niño composite of each simulation is multiplied by the number needed to get the same proportion of events as in the PI) and find that this reduction in the fraction of Pacific discharge due to El Niño is mainly due to the reduced occurrence of El Niño events in the $\mathrm{MH}$ (rather than to their reduced amplitude). For example, the fraction due to El Niño for the $\operatorname{Rad}_{\mathrm{TOACE}}$ index becomes substantially the same in the MH than in the PI when considering equal El Niño occurrence (not shown).

To summarize, IPSL-CM5A-LR results suggest that the El Niño phenomenon does not keep the same relative role in the Pacific discharge between the $\mathrm{MH}$ and the PI: it is smaller in the MH. This is mainly due to the reduction in the El Niño occurrence. Therefore, the El Niño reduction in the MH is not simply proportional to changes in the background state, but could further be an indicator of its reduced role in discharging the Pacific.

To further support this result, Fig. 17 shows, for the four indices, whether the MH El Niño-related changes are smaller or larger than the MH mean state-related changes. For the four indices, this figure gives the ratio:

$$
\frac{\left[\sum_{\text {Niño months }} \operatorname{Anom}(i)\right]_{M H}}{\left[\sum_{\text {Niño months }} \operatorname{Anom}(i)\right]_{P I}} / \frac{\left[\sum_{\text {all months }} i\right]_{M H}}{\left[\sum_{\text {all months }} i\right]_{P I}},
$$

when considering only 500 years of the PI simulation in order to get the same simulation length (first and last 500 years). The ratio is lower than 1 for the four indices, meaning that the $\mathrm{MH}$ reduction in the integrated Niño anomaly is larger than the reduction in the integrated total value. Thus, the El 


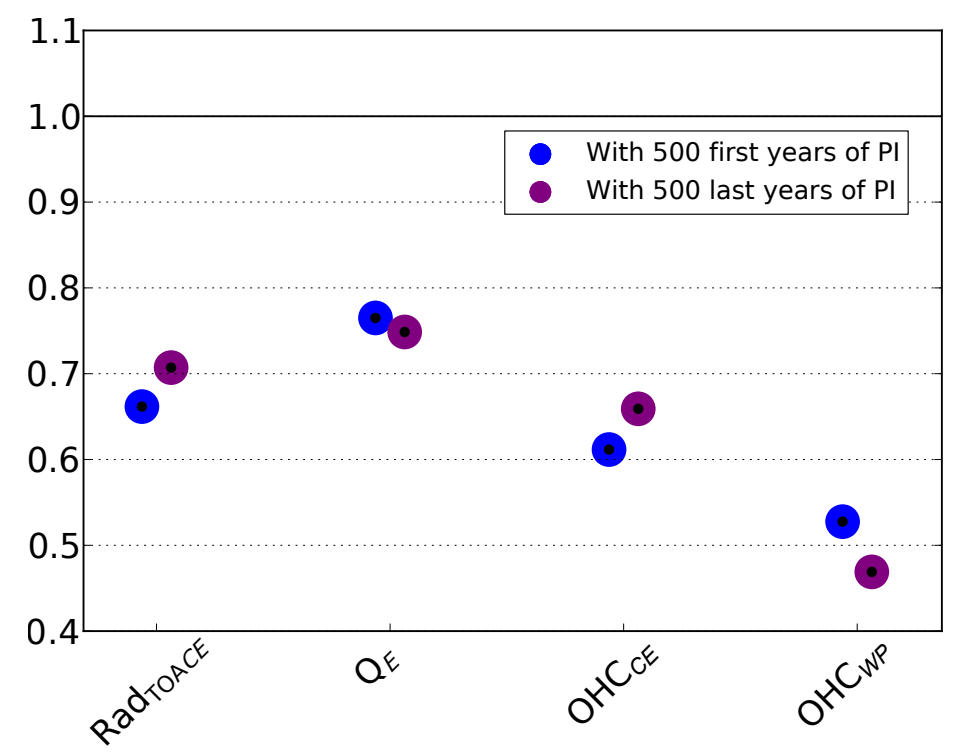

Fig. 17. Ratios comparing the MH El Niño-related changes with mean state-related changes, built from temporal integration as described in the text. Two values are given for each of the four indices: one when considering the first 500 years of the PI simulation (in order to get the same simulation length), and one considering the last 500 years. Ratios are lower to one, meaning that the El Niño-related changes are larger than the mean state-related changes in the MH.

Niño-related changes are larger than the mean state-related changes in the MH.

\section{Summary and discussion}

In this study we explore the role of the tropical Pacific ocean in global energy redistribution, in particular the relative role of El Niño events. We compare the mid-Holocene climate (MH, 6 ka PB) and the pre-industrial (PI, $0 \mathrm{ka}$ ), as simulated by two experiments using the IPSL-CM5A-LR model.

In the $\mathrm{MH}$ experiment, the tropical Pacific ocean provides less energy to the entire globe than in the PI experiment, in long-term mean. This is partly a direct response of the reduced annual mean insolation in the tropics, but this response is further amplified by internal processes (feedbacks, albedo, large-scale circulation, etc.). In other words, in the IPSL-CM5A-LR MH experiment, the long-term mean energy export out of the tropical Pacific is smaller than expected from insolation forcing.

El Niño events contribute to global energy redistribution, by exporting energy out of the Pacific. In the IPSL-CM5A-LR PI experiment, the signature of a "typical" El Niño event (composite of all the El Niño events) on global energetics is the following: heat is discharged from the western Pacific warm pool and transferred to the eastern Pacific; surface waters warming in the eastern Pacific brings energy to the atmosphere via radiative and evaporative cooling; the atmospheric column above the entire Pacific charges up in energy, exports this energy poleward and more largely towards Indian and Atlantic oceans areas. Results of this experiment are consistent with observations and reanalyses, although the role of infrared radiations in heating the atmosphere above the Pacific ocean is overestimated.

In the $\mathrm{MH}$ experiment, the El Niño-related warm pool discharge, atmospheric diabatic heating and MSE export over the equatorial Pacific are smaller. This is consistent with weaker ENSO in the MH. The energy export out of the tropical Pacific is reduced both in long-term mean and during El Niño years. However, the latter is not proportional to the former, meaning that the fraction of Pacific discharge that is due to El Niño is reduced in the MH experiment. This is mainly due to the reduction in the occurrence of El Niño events. Thus, the El Niño-related changes associated with the MH experiment are larger than its mean state-related changes.

To summarize, in the IPSL-CM5A-LR MH experiment, the role of energy pump played by the tropical Pacific is reduced compared to the PI experiment, both in long-term mean and during El Niño years. This suggests that there could be coherence between weaker "capacity" of the tropical Pacific as being a source of energy in long-term mean, and weaker El Niño.

At this stage, this work gives a new vision for studying El Niño in a changing climate, from a global energetic point of view. El Niño is viewed as a component of a closed system in which the energy is conserved. The El Niño change is seen from the perspective of its "final" signature on global energetics, which is the result of all the internal physical processes that lead to this change. By identifying the 
processes that become dominant in global energy redistribution, we could understand more about these internal processes and thus about the El Niño reduction in the MH. Our results are likely to be model dependent, but the goal of this paper is to put emphasis on energetic diagnoses and new questions about the energetic role of El Niño.

This work shows that the change in the energetic role of the Pacific ocean is a key element to address the change in El Niño. It would be interesting to apply this method to other past climates or to future projections.

\section{Methods}

Estimation of 90\% confidence intervals in Figs. 2 and 11 (left panels) or 50\% confidence intervals in Fig. 15 (left and bottom panels) from bootstrap resampling: For each simulation (PI and MH), 100 estimations of the variable of interest (zonal averages of mean surface temperature, mean rainfall, mean OHC, zonal integration of mean $\operatorname{Rad}_{\mathrm{TOA}}$, or zonal and meridional integrations of El Niño composite of MSE transport anomaly) are produced by randomly sampling 100 samples in the original dataset (of the same size, with 1 year $=1$ value). 10000 estimations of the MH-PI difference are then obtained, by subtracting successively the 100 estimations of the PI to each of the 100 estimations of the MH. The $90 \%$ confidence interval consists of the percentiles $5-95 \%$. The $50 \%$ confidence interval consists of the percentiles $25-75 \%$.

Estimation of 90\% confidence intervals in Figs. 13 and 9, for the maps in Figs. 8 and 10, or 50\% confidence intervals in Fig. 14 and for the map in Fig. 15, from bootstrap resampling: 5,000 estimations of El Niño composite anomaly are produced by randomly sampling 5,000 samples in the original dataset (of $125 \mathrm{El}$ Niño events in the PI and 39 in the MH) of the same size. The $90 \%$ confidence interval consists of the percentiles 5-95\%. The 50\% confidence interval consists of the percentiles $25-75 \%$.

\section{Acknowledgments}

This work was supported by the French ANR Project ELPASO (no. 2010 BLANC 608 01), and by the Knowledge and Innovation Community Climate-KIC from the European Institute of Innovation and Technology (EIT). We acknowledge the World Climate Research Programme's Working Group on Coupled Modelling, which is responsible for CMIP, and we thank the PMIP3 modelling groups for producing and making available their model output. For CMIP the U.S. Department of Energy's Program for Climate Model Diagnosis and Intercomparison provides coordinating support and led development of software infrastructure in partnership with the Global Organization for Earth System Science Portals. This study benefited from the IPSL Prodiguer-Ciclad facility which is supported by CNRS, UPMC, Labex L-IPSL which is funded by the ANR (Grant \#ANR-10-LABX-0018) and by the European FP7 IS-ENES2 project (Grant \#312979). The computing time was provided by GENCI (Grand Equipement National de Calcul Intensif) and the simulations performed on Curie at TGCC (CEA, France). We acknowledge the three anonymous reviewers for their relevant comments, which led to improve the manuscript.

The authors acknowledge Climate Dynamics and Springer who provided the original source of publication. 


\section{References}

An SI, Choi J (2013) Mid-Holocene tropical Pacific climate state, annual cycle, and ENSO in PMIP2 and PMIP3. Climate Dynamics pp 1-14, DOI 10.1007/s00382-013-1880-z, URL http://link.springer.com/article/10. $1007 / \mathrm{s} 00382-013-1880-\mathrm{z}$

Bellenger H, Guilyardi E, Leloup J, Lengaigne M, Vialard J (2014) ENSO representation in climate models: from CMIP3 to CMIP5. Climate Dynamics 42(7-8):1999-2018, DOI 10.1007/s00382-013-1783-z, URL http: //link.springer.com/article/10.1007/s00382-013-1783-z

Berger A (1978) Long-Term Variations of Daily Insolation and Quaternary Climatic Changes. Journal of the Atmospheric Sciences 35(12):2362-2367, DOI 10.1175/1520-0469(1978)035<2362:LTVODI>2.0.CO;2, URL http://journals.ametsoc.org/doi/abs/10.1175/1520-0469(1978)035\%3C2362:LTVODI\%3E2.0.C0;2

Bjerknes J (1969) Atmospheric teleconnections from the equatorial pacific1. Monthly Weather Review 97(3):163172, DOI 10.1175/1520-0493(1969)097<0163:ATFTEP>2.3.CO;2, URL http://journals.ametsoc.org/doi/ abs/10.1175/1520-0493(1969)097\%3C0163:ATFTEP\%3E2.3.C0\%3B2

Braconnot P, Kageyama M (2015) Shortwave forcing and feedbacks in Last Glacial Maximum and Mid-Holocene PMIP3 simulations. Phil Trans R Soc A 373(2054):20140,424, DOI 10.1098/rsta.2014.0424, URL http://rsta. royalsocietypublishing.org/content/373/2054/20140424

Braconnot P, Marti O, Joussaume S, Leclainche Y (2000) Ocean Feedback in Response to 6 kyr BP Insolation. Journal of Climate 13(9):1537-1553, DOI 10.1175/1520-0442(2000)013<1537:OFIRTK > 2.0.CO;2, URL http: //journals.ametsoc.org/doi/abs/10.1175/1520-0442(2000)013\%3C1537:OFIRTK\%3E2.0.CO;2

Braconnot P, Marzin C, Grégoire L, Mosquet E, Marti O (2008) Monsoon response to changes in Earth's orbital parameters: comparisons between simulations of the Eemian and of the Holocene. Climate of the Past Discussions 4(2):459-493, URL http://hal.archives-ouvertes.fr/hal-00330744

Braconnot P, Harrison SP, Kageyama M, Bartlein PJ, Masson-Delmotte V, Abe-Ouchi A, Otto-Bliesner B, Zhao Y (2012a) Evaluation of climate models using palaeoclimatic data. Nature Climate Change 2(6):417-424, DOI 10.1038/nclimate1456, URL http://www. nature.com/nclimate/journal/v2/n6/full/nclimate1456.html

Braconnot P, Luan Y, Brewer S, Zheng W (2012b) Impact of Earth's orbit and freshwater fluxes on Holocene climate mean seasonal cycle and ENSO characteristics. Climate Dynamics 38(5-6):1081-1092, DOI 10.1007/ s00382-011-1029-x, URL http://link. springer.com/article/10.1007/s00382-011-1029-x

Brown J, Tudhope AW, Collins M, McGregor HV (2008) Mid-Holocene ENSO: Issues in quantitative model-proxy data comparisons. Paleoceanography 23(3), DOI 10.1029/2007PA001512, URL http://onlinelibrary.wiley. com/doi/10.1029/2007PA001512/abstract

Carré M, Sachs JP, Schauer AJ, Rodríguez WE, Ramos FC (2013) Reconstructing El Niño-Southern Oscillation activity and ocean temperature seasonality from short-lived marine mollusk shells from Peru. Palaeogeography, Palaeoclimatology, Palaeoecology 371:45-53, DOI 10.1016/j.palaeo.2012.12.014, URL http://www . sciencedirect.com/science/article/pii/S0031018212006967

Clement AC, Seager R, Cane MA (2000) Suppression of El Niño during the Mid-Holocene by changes in the Earth's orbit. Paleoceanography 15(6):731-737, DOI 10.1029/1999PA000466, URL http://onlinelibrary . wiley.com/doi/10.1029/1999PA000466/abstract

Cobb KM, Westphal N, Sayani HR, Watson JT, Di Lorenzo E, Cheng H, Edwards RL, Charles CD (2013) Highly Variable El Nino-Southern Oscillation Throughout the Holocene. Science 339(6115):67-70, DOI 10. 1126/science.1228246, URL http://www.sciencemag.org/cgi/doi/10.1126/science.1228246

Dufresne JL, Foujols MA, Denvil S, Caubel A, Marti O, Aumont O, Balkanski Y, Bekki S, Bellenger H, Benshila R, Bony S, Bopp L, Braconnot P, Brockmann P, Cadule P, Cheruy F, Codron F, Cozic A, Cugnet D, Noblet Nd, Duvel JP, Ethé C, Fairhead L, Fichefet T, Flavoni S, Friedlingstein P, Grandpeix JY, Guez L, Guilyardi E, Hauglustaine D, Hourdin F, Idelkadi A, Ghattas J, Joussaume S, Kageyama M, Krinner G, Labetoulle S, Lahellec A, Lefebvre MP, Lefevre F, Levy C, Li ZX, Lloyd J, Lott F, Madec G, Mancip M, Marchand M, Masson S, Meurdesoif Y, Mignot J, Musat I, Parouty S, Polcher J, Rio C, Schulz M, Swingedouw D, Szopa S, Talandier C, Terray P, Viovy N, Vuichard N (2013) Climate change projections using the IPSL-CM5 Earth System Model: from CMIP3 to CMIP5. Climate Dynamics 40(9-10):2123-2165, DOI 10.1007/s00382-012-1636-1, URL http://link.springer.com/article/10.1007/s00382-012-1636-1

Duprey N, Lazareth CE, Corrège T, Le Cornec F, Maes C, Pujol N, Madeng-Yogo M, Caquineau S, Soares Derome C, Cabioch G (2012) Early mid-Holocene SST variability and surface-ocean water balance in the southwest Pacific. Paleoceanography 27(4), DOI 10.1029/2012PA002350, URL http://onlinelibrary.wiley.com/doi/ 10.1029/2012PA002350/abstract 
Emile-Geay J, Cobb KM, Carré M, Braconnot P, Leloup J, Zhou Y, Harrison SP, Corrège T, McGregor HV, Collins M, Driscoll R, Elliot M, Schneider B, Tudhope A (2015) Links between tropical Pacific seasonal, interannual and orbital variability during the Holocene. Nature Geoscience DOI 10.1038/ngeo2608, URL http: //www. nature.com/doifinder/10.1038/ngeo2608

Fasullo JT, Trenberth KE (2008) The Annual Cycle of the Energy Budget. Part II: Meridional Structures and Poleward Transports. Journal of Climate 21(10):2313-2325, DOI 10.1175/2007JCLI1936.1, URL http: //journals.ametsoc.org/doi/abs/10.1175/2007JCLI1936.1

Fichefet T, Maqueda MAM (1997) Sensitivity of a global sea ice model to the treatment of ice thermodynamics and dynamics. Journal of Geophysical Research: Oceans 102(C6):12,609-12,646, DOI 10.1029/97JC00480, URL http://onlinelibrary.wiley.com/doi/10.1029/97JC00480/abstract

Hasegawa T, Hanawa K (2003) Heat Content Variability Related to ENSO Events in the Pacific. Journal of Physical Oceanography 33(2):407-421, DOI 10.1175/1520-0485(2003)033<0407:HCVRTE $>2.0$.CO;2, URL http: //journals.ametsoc.org/doi/abs/10.1175/1520-0485\%282003\%29033\%3C0407\%3AHCVRTE\%3E2.0.CO\%3B2

Hourdin F, Musat I, Bony S, Braconnot P, Codron F, Dufresne JL, Fairhead L, Filiberti MA, Friedlingstein P, Grandpeix JY, Krinner G, LeVan P, Li ZX, Lott F (2006) The LMDZ4 general circulation model: climate performance and sensitivity to parametrized physics with emphasis on tropical convection. Climate Dynamics 27(7-8):787-813, DOI 10.1007/s00382-006-0158-0, URL http://link.springer.com/article/10. $1007 / \mathrm{s} 00382-006-0158-0$

Jin FF (1997) An Equatorial Ocean Recharge Paradigm for ENSO. Part I: Conceptual Model. Journal of the Atmospheric Sciences 54(7):811-829, DOI 10.1175/1520-0469(1997)054<0811:AEORPF > 2.0.CO;2, URL http: //journals.ametsoc.org/doi/abs/10.1175/1520-0469\%281997\%29054\%3C0811\%3AAEORPF\%3E2.0.CO\%3B2

Joussaume S, Taylor KE, Braconnot P, Mitchell JFB, Kutzbach JE, Harrison SP, Prentice IC, Broccoli AJ, AbeOuchi A, Bartlein PJ, Bonfils C, Dong B, Guiot J, Herterich K, Hewitt CD, Jolly D, Kim JW, Kislov A, Kitoh A, Loutre MF, Masson V, McAvaney B, McFarlane N, de Noblet N, Peltier WR, Peterschmitt JY, Pollard D, Rind D, Royer JF, Schlesinger ME, Syktus J, Thompson S, Valdes P, Vettoretti G, Webb RS, Wyputta U (1999) Monsoon changes for 6000 years ago: Results of 18 simulations from the Paleoclimate Modeling Intercomparison Project (PMIP). Geophysical Research Letters 26(7):859-862, DOI 10.1029/1999GL900126, URL http://onlinelibrary.wiley.com/doi/10.1029/1999GL900126/abstract

Kageyama M, Braconnot P, Bopp L, Caubel A, Foujols MA, Guilyardi E, Khodri M, Lloyd J, Lombard F, Mariotti V, Marti O, Roy T, Woillez MN (2013) Mid-Holocene and Last Glacial Maximum climate simulations with the IPSL model_part I: comparing IPSL_cm5a to IPSL_cm4. Climate Dynamics 40(9-10):2447-2468, DOI 10.1007/s00382-012-1488-8, URL http://Iink. springer.com/article/10.1007/s00382-012-1488-8

Karamperidou C, Di Nezio PN, Timmermann A, Jin FF, Cobb KM (2015) The response of ENSO flavors to mid-Holocene climate: Implications for proxy interpretation: ENSO FLAVORS IN THE MIDHOLOCENE. Paleoceanography 30(5):527-547, DOI 10.1002/2014PA002742, URL http://doi.wiley.com/ $10.1002 / 2014 \mathrm{PA002742}$

Klein SA, Soden BJ, Lau NC (1999) Remote Sea Surface Temperature Variations during ENSO: Evidence for a Tropical Atmospheric Bridge. Journal of Climate 12(4):917-932, DOI 10.1175/1520-0442(1999) $012<0917$ :RSSTVD>2.0.CO;2, URL http://journals.ametsoc.org/doi/abs/10.1175/1520-0442\%281999\% $29012 \% 3$ C0917\%3ARSSTVD $\% 3 E 2$. 0.CO\%3B2

Krinner G, Viovy N, de Noblet-Ducoudré N, Ogée J, Polcher J, Friedlingstein P, Ciais P, Sitch S, Prentice IC (2005) A dynamic global vegetation model for studies of the coupled atmosphere-biosphere system. Global Biogeochemical Cycles 19(1), DOI 10.1029/2003GB002199, URL http://onlinelibrary.wiley.com/doi/10. 1029/2003GB002199/abstract

Kutzbach JE, Otto-Bliesner BL (1982) The Sensitivity of the African-Asian Monsoonal Climate to Orbital Parameter Changes for 9000 Years B.P. in a Low-Resolution General Circulation Model. Journal of the Atmospheric Sciences 39(6):1177-1188, DOI 10.1175/1520-0469(1982)039<1177:TSOTAA $>2.0$.CO;2, URL http://journals.ametsoc.org/doi/abs/10.1175/1520-0469(1982)039\%3C1177:TSOTAA\%3E2.0.C0;2

Li L, Wang B, Zhang GJ (2015) The Role of Moist Processes in Shortwave Radiative Feedback during ENSO in the CMIP5 Models. Journal of Climate 28(24):9892-9908, DOI 10.1175/JCLI-D-15-0276.1, URL http: //journals.ametsoc.org/doi/10.1175/JCLI-D-15-0276.1

Liu Z (2002) A Simple Model Study of ENSO Suppression by External Periodic Forcing*. Journal of Climate 15(9):1088-1098, DOI 10.1175/1520-0442(2002)015<1088:ASMSOE>2.0.CO;2, URL http://journals . ametsoc.org/doi/full/10.1175/1520-0442(2002)015\%3C1088:ASMSOE\%3E2.0.CO\%3B2 
Liu Z, Kutzbach J, Wu L (2000) Modeling climate shift of El Nino variability in the Holocene. Geophysical Research Letters 27(15):2265-2268, DOI 10.1029/2000GL011452, URL http://onlinelibrary.wiley.com/ doi/10.1029/2000GL011452/abstract

Luan Y, Braconnot P, Yu Y, Zheng W, Marti O (2012) Early and mid-Holocene climate in the tropical Pacific: seasonal cycle and interannual variability induced by insolation changes. Clim Past 8(3):1093-1108, DOI 10.5194/cp-8-1093-2012, URL http://www.clim-past.net/8/1093/2012/

Luan Y, Braconnot P, Yu Y, Zheng W (2015) Tropical Pacific mean state and ENSO changes: sensitivity to freshwater flux and remnant ice sheets at $9.5 \mathrm{ka}$ BP. Climate Dynamics pp 1-18, DOI 10.1007/s00382-015-2467-7, URL http://link.springer.com/article/10.1007/s00382-015-2467-7

Madec G, Delecluse P, Imbard M, Lévy C (1997) OPA version 8. Ocean General Circulation Model reference manual. Rapp Int, LODYC, France p 200

Mantsis DF, Clement AC, Broccoli AJ, Erb MP (2011) Climate Feedbacks in Response to Changes in Obliquity. Journal of Climate 24(11):2830-2845, DOI 10.1175/2010JCLI3986.1, URL http://journals.ametsoc.org/ doi/abs/10.1175/2010JCLI3986.1

Marti O, Braconnot P, Dufresne JL, Bellier J, Benshila R, Bony S, Brockmann P, Cadule P, Caubel A, Codron F, Noblet Nd, Denvil S, Fairhead L, Fichefet T, Foujols MA, Friedlingstein P, Goosse H, Grandpeix JY, Guilyardi E, Hourdin F, Idelkadi A, Kageyama M, Krinner G, Lévy C, Madec G, Mignot J, Musat I, Swingedouw D, Talandier C (2010) Key features of the IPSL ocean atmosphere model and its sensitivity to atmospheric resolution. Climate Dynamics 34(1):1-26, DOI 10.1007/s00382-009-0640-6, URL http://link. springer.com/ article/10.1007/s00382-009-0640-6

Mayer M, Haimberger L (2012) Poleward Atmospheric Energy Transports and Their Variability as Evaluated from ECMWF Reanalysis Data. Journal of Climate 25(2):734-752, DOI 10.1175/JCLI-D-11-00202.1, URL http://journals. ametsoc.org/doi/abs/10.1175/JCLI-D-11-00202.1

Mayer M, Trenberth KE, Haimberger L, Fasullo JT (2013) The Response of Tropical Atmospheric Energy Budgets to ENSO*. Journal of Climate 26(13):4710-4724, DOI 10.1175/JCLI-D-12-00681.1, URL http://journals . ametsoc.org/doi/abs/10.1175/JCLI-D-12-00681.1

Mayer M, Haimberger L, Balmaseda MA (2014) On the Energy Exchange between Tropical Ocean Basins Related to ENSO. Journal of Climate 27(17):6393-6403, DOI 10.1175/JCLI-D-14-00123.1, URL http://journals. ametsoc.org/doi/full/10.1175/JCLI-D-14-00123.1

McGregor HV, Gagan MK (2004) Western Pacific coral delta18o records of anomalous Holocene variability in the El Niño-Southern Oscillation. Geophysical Research Letters 31(11), DOI 10.1029/2004GL019972, URL http://onlinelibrary.wiley.com/doi/10.1029/2004GL019972/abstract

McGregor S, Spence P, Schwarzkopf FU, England MH, Santoso A, Kessler WS, Timmermann A, Böning CW (2014) ENSO-driven interhemispheric Pacific mass transports. Journal of Geophysical Research: Oceans 119(9):6221-6237, DOI 10.1002/2014JC010286, URL http://onlinelibrary.wiley.com/doi/10. 1002/2014JC010286/abstract

Moy CM, Seltzer GO, Rodbell DT, Anderson DM (2002) Variability of El Niño/Southern Oscillation activity at millennial timescales during the Holocene epoch. Nature 420(6912):162-165, DOI 10.1038/nature01194, URL http://www . nature.com/nature/journal/v420/n6912/full/nature01194.html

Oort AH, Yienger JJ (1996) Observed Interannual Variability in the Hadley Circulation and Its Connection to ENSO. Journal of Climate 9(11):2751-2767, DOI 10.1175/1520-0442(1996)009<2751:OIVITH >2.0.CO;2, URL http://journals.ametsoc.org/doi/abs/10.1175/1520-0442(1996)009\%3C2751:0IVITH\%3E2.0.CO; 2

Pan A, Liu Q, Liu Z (2005) Periodic Forcing and ENSO Suppression in the Cane-Zebiak Model. Journal of Oceanography 61(1):109-113, DOI 10.1007/s10872-005-0023-5, URL http://link.springer.com/article/ $10.1007 / \mathrm{s} 10872-005-0023-5$

Sadekov AY, Ganeshram R, Pichevin L, Berdin R, McClymont E, Elderfield H, Tudhope AW (2013) Palaeoclimate reconstructions reveal a strong link between El Nino-Southern Oscillation and Tropical Pacific mean state. Nature Communications 4, DOI 10.1038/ncomms3692, URL http://ww. nature.com.biblioplanets.gate. inist.fr/ncomms/2013/131101/ncomms3692/full/ncomms3692.html

Saint-Lu M, Braconnot P, Leloup J, Lengaigne M, Marti O (2015) Changes in the ENSO/SPCZ relationship from past to future climates. Earth and Planetary Science Letters 412:18-24, DOI 10.1016/j.epsl.2014.12.033, URL http://linkinghub.elsevier.com/retrieve/pii/S0012821X14007948 
Taylor KE, Stouffer RJ, Meehl GA (2012) An Overview of CMIP5 and the Experiment Design. Bulletin of the American Meteorological Society 93(4):485-498, DOI 10.1175/BAMS-D-11-00094.1, URL http://journals . ametsoc.org/doi/abs/10.1175/BAMS-D-11-00094.1

Trenberth KE, Fasullo JT (2013) An apparent hiatus in global warming? Earth's Future 1(1):19-32, DOI 10.1002/2013EF000165, URL http://onlinelibrary.wiley.com/doi/10.1002/2013EF000165/abstract

Trenberth KE, Stepaniak DP, Caron JM (2002) Interannual variations in the atmospheric heat budget. Journal of Geophysical Research: Atmospheres 107(D8):AAC 4-1, DOI 10.1029/2000JD000297, URL http: //onlinelibrary.wiley.com/doi/10.1029/2000JD000297/abstract

Tudhope AW, Chilcott CP, McCulloch MT, Cook ER, Chappell J, Ellam RM, Lea DW, Lough JM, Shimmield GB (2001) Variability in the El Niño-Southern Oscillation Through a Glacial-Interglacial Cycle. Science 291(5508):1511-1517, DOI 10.1126/science.1057969, URL http://www.sciencemag.org/content/291/5508/ 1511

Valcke S (2006) OASIS3 user guide (prism $\left.\backslash \_2-5\right)$. PRISM support initiative report 3:64

Wyrtki K (1975) El Niño-The Dynamic Response of the Equatorial Pacific Oceanto Atmospheric Forcing. Journal of Physical Oceanography 5(4):572-584, DOI 10.1175/1520-0485(1975)005<0572:ENTDRO > 2.0.CO;2, URL http://journals.ametsoc.org/doi/abs/10.1175/1520-0485(1975)005\%3C0572:ENTDR0\%3E2.0.C0\%3B2

Zhao Y, Harrison SP (2011) Mid-Holocene monsoons: a multi-model analysis of the inter-hemispheric differences in the responses to orbital forcing and ocean feedbacks. Climate Dynamics 39(6):1457-1487, DOI 10.1007/ s00382-011-1193-z, URL http://link. springer.com/article/10.1007/s00382-011-1193-z

Zhao Y, Braconnot P, Marti O, Harrison SP, Hewitt C, Kitoh A, Liu Z, Mikolajewicz U, Otto-Bliesner B, Weber SL (2005) A multi-model analysis of the role of the ocean on the African and Indian monsoon during the midHolocene. Climate Dynamics 25(7-8):777-800, DOI 10.1007/s00382-005-0075-7, URL http://link. springer. $\mathrm{com} /$ article/10.1007/s00382-005-0075-7

Zheng W, Braconnot P, Guilyardi E, Merkel U, Yu Y (2008) ENSO at 6ka and 21ka from ocean-atmosphere coupled model simulations. Climate Dynamics 30(7-8):745-762, DOI 10.1007/s00382-007-0320-3, URL http: //link. springer.com/article/10.1007/s00382-007-0320-3 